TITLE:

\title{
Machining tests to identify kinematic errors on five-axis machine tools
}

\section{AUTHOR(S):}

Ibaraki, Soichi; Sawada, Masahiro; Matsubara, Atsushi; Matsushita, Tetsuya

\section{CITATION:}

Ibaraki, Soichi ... [et al]. Machining tests to identify kinematic errors on five-axis machine tools. Precision Engineering 2010, 34(3): 387-398

ISSUE DATE:

2010-07

URL:

http://hdl.handle.net/2433/113247

\section{RIGHT:}

(C) 2010 Elsevier B.V.; This is not the published version. Please cite only the published version.; この論文は出版社版でありません。引用の際に は出版社版をご確認ご利用ください。 


\title{
Machining Tests to Identify Kinematic Errors on Five-axis Machine Tools
}

\author{
Soichi Ibaraki ${ }^{*}$, Masahiro Sawada ${ }^{1}$, Atsushi Matsubara ${ }^{1}$, and \\ Tetsuya Matsushita ${ }^{2}$ \\ ${ }^{1}$ Department of Micro Engineering, Kyoto University, Yoshida-honmachi, \\ Sakyo-ku, Kyoto 606-8501, Japan. \\ ${ }^{2}$ Okuma Corp, Oguchi-cho, Niwa-gun, Aichi 480-0193, Japan. \\ Type of contribution: Original Research Paper
}

\begin{abstract}
The machining of a cone frustum as specified in NAS (National Aerospace Standard) 979 is widely accepted as a final performance test for five-axis machining centers. Although it gives a good demonstration of the machine's overall machining performance, it is generally difficult to separately identify each error source in the machine from the measured error profile of the finished workpiece. This paper proposes a set of machining tests for a five-axis machine tool to identify its kinematic errors, one of its most fundamental error sources. In each machining pattern, a simple straight side-cutting using a straight end mill is performed. The relationship between geometric errors of the finished workpiece and the machine's kinematic errors is formulated based on the kinematic model of a five-axis machine. The identification of kinematic errors from geometric errors of finished workpieces is experimentally demonstrated on a commercial five-axis machining center, and the estimates are compared to those estimated based on ball bar measurements.
\end{abstract}

Key words: Five-axis machine tools, kinematic errors, measurement, machining test, cone frustum.

\footnotetext{
* Corresponding author. Phone/Fax: +81-75-753-5227

Email address: ibaraki@prec.kyoto-u.ac.jp (Soichi Ibaraki $\left.{ }^{1}\right)$.
} 


\section{Introduction}

Machine tools with two rotary axes to tilt and rotate a tool and/or a workpiece, in addition to three orthogonal linear axes, are collectively called five-axis machine tools. Five-axis machining centers have been rapidly accepted in the world-wide manufacturing market in recent years. Since a fiveaxis machining center has linear and rotary axes that are stacked over each other, motion errors of each axis and its assembly error are accumulated in the positioning error of a tool relative to a workpiece. With the recent rapid popularization of five-axis machining centers, there have been more cases where five-axis machining centers are used in a high-precision machining application such as the machining of high-precision dies/molds. The improvement of their motion accuracies is a crucial demand in the market.

As a basis to improve the motion accuracy of five-axis machines, it is important to develop a methodology to evaluate it in an accurate, and efficient manner. The current ISO standards describe measurement methods to evaluate static position and orientation errors of rotary axes (such errors are collectively called kinematic errors), with a main focus on five-axis machines with a universal spindle (ISO 10791-1 3 [1]). For five-axis machines with a tilting rotary table, there are fewer description in current ISO standards. However, the revision of ISO standards are currently under the discussion in the ISO technical committee TC39/SC2/WG3 such that the standards cover more variety of five-axis machines [2].

In particular, the importance of kinematic errors is well understood by many machine tool manufactures, as one of the most fundamental error factors in a five-axis machine tool. There has been many research works reported in the literature on the identification of kinematic errors based on the measurement of the machine's motion error. The telescoping double ball bar (DBB) has been applied to identify kinematic errors on five-axis machines $[3,4,5,6]$. Bringmann and Knapp [7] presented the "R-Test," where the three-dimensional displacement of a sphere attached to the spindle tip is measured by displacement sensors installed on the table. The inclusion of some of these measurements into the revised ISO standards has been currently discussed in TC39/SC2/WG3 [2]. 
Although it is important to evaluate each kinematic error by using such a non-cutting measurement, typical machine tool users concern more the machine's accuracy when it performs actual machining. The standard, ISO 107917 [8], describes a machining test to evaluate the machine's machining accuracy, but it is only for three-axis machining. In current ISO standards, there is no description of a machining test for five-axis machining. The NAS (National Aerospace Standard) 979 [9] describes a five-axis machining test of a cone frustum. The side surface of cone frustum is machined by using a straight end mill, and the finished workpiece is measured to evaluate the circularity error of circumferences, the concentricity error of top and bottom circumferences, and the angular error of side surface, showing an overall contouring performance of the machine tool. Since it is only standard well known in the industry describing a five-axis machining test, it is widely accepted by many machine tool builders as a final performance test for five-axis machines.

There are important issues with this test. First, since NAS 979 [9], published in 1969, focuses solely on a test for five-axis machines with a universal spindle, it gives some ambiguity when applied to five-axis machines with a tilting rotary table. For example, NAS 979 does not describe the location of the workpiece on the table. On a five-axis machine with a tilting rotary table, the influence of kinematic errors on the overall positioning error may significantly differ depending on it $[10,11]$. Another critical issue is that it is generally quite difficult to diagnose the causes of machining errors. In particular, the identification of the machine's kinematic errors from measured error profiles of the finished workpiece is generally not possible, since multiple kinematic errors may result in exactly the same geometric error profiles, which can be easily understand by using, for example, the machining simulator presented by Uddin et al. [12].

The objective of this paper is to propose new machining tests for five-axis machine tools such that error sources in the machine tool can be separately identified by evaluating the geometric error of the machined workpiece. As one of the most fundamental error sources in a five-axis machine tool, this paper focuses on the diagnosis of kinematic errors. To the authors' knowledge, there 
have been few studies found in the literature proposing a machining test for five-axis machine tools. Ohashi et al.'s work [13] can be seen as the extension of the machining test in ISO 10791-7 [8] to five-axis machining. In this test, the geometry of the machined workpiece is complex, which requires longer time and more complex setup for the pre-machining. The geometry of the test piece must be as simple as possible to shorten the test time, and to facilitate the measurement. The NCG recommendation 2005 [14] also presents a test workpiece for five-axis simultaneous machining. Its geometry is also quite complex and the diagnosis of error sources is not presented at all.

\section{Kinematic model of a five-axis machine tool}

\subsection{Machine configuration}

There are many different configurations of five-axis machining centers currently available in the market [6]. In this study, a five-axis machining center with a tilting rotary table, or ZX/YAC configuration [15], is considered as the target. Figure 1 illustrates its configuration. The machine has three linearaxis drives $(\mathrm{X}, \mathrm{Y}, \mathrm{Z})$ and two rotary-axis drives $(\mathrm{A}, \mathrm{C})$ for generating rotary motions about $\mathrm{X}$ and $\mathrm{Z}$ axes, respectively. Although this paper only considers this configuration, it must be emphasized that the basic idea of this paper can be straightforwardly extended to any configurations of five-axis machines.

\subsection{Kinematic errors to be identified}

Inasaki et al. [16] have showed that eleven kinematic errors are sufficient to define the kinematic model to describe relative location and orientation of the tool to the workpiece on the machine configuration depicted in Fig. 1. Table 1 shows this sufficient set of kinematic errors. The objective of machining tests presented in this paper is to identify eight kinematic errors associated with rotary axes. The squareness errors of linear axes, $\gamma_{Y X}, \alpha_{Z Y}$, and $\beta_{Z X}$, are easier to directly measure (ISO 10791-2 [1]), and thus they are assumed to be known in this study. The definition of each kinematic error can be also understood in the kinematic model presented in Section 2.3. 


\subsection{Kinematic modeling of five-axis machine tool with kinematic errors}

The kinematic model is used to compute the position of the tool center with respect to the workpiece under the existence of kinematic errors $[17,18]$. This section briefly reviews the kinematic model of the machine configuration in Fig. 1 [16,12].

Define the reference frame as the coordinate system fixed to the machine frame or bed. Suppose that the commanded position of X, Y, Z, A, and C axes is respectively given as $\hat{X}, \hat{Y}, \hat{Z}, \hat{A}$, and $\hat{C}$ in the reference frame. The tool center location in the reference frame under the existence of kinematic errors is denoted by ${ }^{r} p \in \mathbb{R}^{4}$ :

$$
{ }^{r} p={ }^{r} T_{x}{ }^{x} T_{z} p_{0}
$$

where $p_{0}=\left[\begin{array}{llll}0 & 0 & 0 & 1\end{array}\right]^{T}$. First three elements of ${ }^{r} p$ represent $\mathrm{X}, \mathrm{Y}$ and $\mathrm{Z}$ coordinates and its fourth element is one. Note that the left-side superscript $r$ denotes the vector defined in the reference frame. ${ }^{r} T_{x} \in \mathbb{R}^{4 \times 4}$ is a homogeneous transformation matrix (HTM) representing the motion of the $\mathrm{X}$ axis in the reference frame. Similarly, ${ }^{x} T_{z} \in \mathbb{R}^{4 \times 4}$ denotes a HTM representing the motion of the $\mathrm{Z}$ axis with respect to the $\mathrm{X}$ axis. They are respectively given by:

$$
\begin{aligned}
{ }^{r} T_{x} & =D^{1}(\hat{X}) \\
{ }^{x} T_{z} & =D^{4}\left(\alpha_{Z Y}\right) D^{5}\left(\beta_{Z X}\right) D^{3}(\hat{Z})
\end{aligned}
$$

where $D^{1}(x), D^{2}(y)$, and $D^{3}(z)$ respectively represent the HTM for linear motions in X-, Y-, and Z-directions, and $D^{4}(a), D^{5}(b)$, and $D^{6}(c)$ respectively represent the HTM for angular motions about X, Y and Z axes. See e.g. [17,18] for the formulation of each HTM.

Define the workpiece frame as the coordinate system attached to the rotary table. The HTM representing the transformation from the workpiece frame to the reference frame is given by:

$$
{ }^{r} T_{w}={ }^{r} T_{y}^{y} T_{a}{ }^{a} T_{c}
$$

where the HTMs, ${ }^{r} T_{y},{ }^{y} T_{a},{ }^{a} T_{c} \in \mathbb{R}^{4 \times 4}$ are respectively given as:

$$
\begin{aligned}
& { }^{a} T_{c}=D^{2}\left(\delta y_{C A}\right) D^{5}\left(\beta_{C A}\right) D^{6}(-\hat{C}) \\
& { }^{y} T_{a}=D^{1}\left(\delta x_{A Y}\right) D^{2}\left(\delta y_{A Y}\right) D^{3}\left(\delta z_{A Y}\right) D^{4}\left(\alpha_{A Y}\right) D^{5}\left(\beta_{A Y}\right) D^{6}\left(\gamma_{A Y}\right) D^{4}(-\hat{A}) \quad(4) \\
& { }^{r} T_{y}=D^{6}\left(-\gamma_{Y X}\right) D^{2}(-\hat{Y})
\end{aligned}
$$


Hence, the tool center location in the workpiece frame, ${ }^{w} p \in \mathbb{R}^{4}$, can be given as follows. Note that the left-side superscript $w$ denotes the vector defined in the workpiece frame.

$$
{ }^{w} p=\left({ }^{r} T_{w}\right)^{-1} \cdot{ }^{r} p
$$

\section{Machining tests to identify kinematic errors}

This section proposes total 11 machining patterns. All the patterns are machined by using a straight end mill. The feed direction is chosen such that the cutting becomes the down-cut. It is not required to perform all the machining patterns to identify all kinematic errors. Section 4 will discuss the choice of machining patterns.

\subsection{Machining Pattern 1-a}

(1) Machining Procedure

Figure 2(a) illustrates Machining Pattern 1-a. The rotary table is placed horizontally by the $\mathrm{A}$-axis (define this angle as $A=0$ ). First, place the workpiece at the $-Y$ location in Fig. 2(a), and perform a side cutting as shown in (a) (c). Then, rotate the rotary table by $C=-180^{\circ}$ and perform a side cutting as shown in (d). Figure 2(b) illustrates the finished workpiece, assuming that it is placed at the $-Y$ location in Fig. 2(a). Machining steps (a) and (b) make first-level steps, which is used as a reference to evaluate geometric errors of second-level steps generated by machining steps (c) and (d).

The workpiece coordinate system $X_{w} Y_{w} Z_{w}$ shown in Fig. 2(b) is defined such that: (i) the $X_{w} Y_{w}$ plane is parallel to the plane containing bottom surfaces generated by machining steps (a) and (b) (in practice, this plane is defined by using the least square fit), and (ii) the $X_{w}$ direction is parallel to the side surface generated by machining step (a). In Fig. 2(b), $\tilde{L}_{0}$ and $\tilde{L}$ denote the nominal width in the $Y_{w}$-direction of first- and second-level steps, respectively. $\tilde{H}_{0}$ and $\tilde{H}$ represent the nominal height in the $Z_{w}$-direction of first- and second-level bottom surface, respectively, from the center line of the A-axis. $\tilde{h}$ is the nominal height in the $Z_{w}$-direction of first- and second-level steps. $\tilde{W}$ is the nominal width of the workpiece in the $X_{w}$-direction. 
$\left(C_{x}, C_{y}\right)$ is the center location of the workpiece at $C=0$ in the reference frame. Note that $\left(C_{x}, C_{y}\right)$ is defined under $A=C=0$ in all the machining patterns. It is assumed that $C_{y}<0$ and $\left|C_{y}\right| \gg\left|C_{x}\right|$.

(2) Formulation of geometric errors of the finished workpiece

Let $S_{a}$ and $S_{b}$ denote an intersecting line of side surfaces generated by machining steps (a) and (b), respectively, and the $X_{w} Y_{w}$ plane at the height $Z_{w}=\tilde{H}_{0}+\frac{1}{2} \tilde{h}$ from the A axis. Similarly, $S_{c}$ and $S_{d}$ denote an intersecting line of side surfaces generated by (c) and (d), respectively, and the $X_{w} Y_{w}$ plane at the height $Z_{w}=\tilde{H}+\frac{1}{2} \tilde{h}$. As is illustrated in Fig. 2(c), let $L_{0}^{1 a} \in \mathbb{R}$ denote the distance between $S_{a}$ and $S_{b}$. Here, the distance of two lines is defined as the distance between the midpoint of each line. Similarly, $L^{1 a} \in \mathbb{R}$ represents the distance between $S_{c}$ and $S_{d}$. Define $\Delta L_{0}^{1 a}:=L_{0}^{1 a}-\tilde{L}_{0}$ and $\Delta L^{1 a}:=L^{1 a}-\tilde{L}$. Let $\theta^{1 a} \in \mathbb{R}$ denote the angle of $S_{c}$ to $S_{d}$ around the $Z_{w}$ axis.

Similarly, let $B_{a}, B_{b}, B_{c}$, and $B_{d}$ denote an intersecting line of bottom surfaces generated by $(\mathrm{a}) \sim(\mathrm{d})$, respectively, and the $X_{w} Z_{w}$ plane at the center of each bottom surface. As is illustrated in Fig. 2(d), let $\Delta H^{1 a} \in \mathbb{R}$ denote the distance between $B_{c}$ and $B_{d}$. Let $\phi^{1 a} \in \mathbb{R}$ denote the angle of $B_{c}$ to $B_{d}$ around the $Y_{w}$ axis.

We assume that the machine tool has no error source but kinematic errors described in Table 1, and that kinematic errors are sufficiently small compared to the workpiece geometry. The influence of each kinematic error on the geometric error of the finished workpiece by Machining Pattern 1-a is formulated as follows:

(i) $\delta y_{C A}$

$\delta y_{C A}$ can be interpreted as an error in the $Y$ location of the rotation center of $\mathrm{C}$-axis with respect to the A-axis from that assumed in the $\mathrm{CNC}$. As is illustrated in Fig. 3, when $\delta y_{C A}>0$ (and all the other kinematic errors are zero), the workpiece location at the machining step (d) with respect to the tool is shifted to the $+Y$ direction by the distance $2 \delta y_{C A}$. Therefore, we have: 


$$
\Delta L^{1 a}=2 \delta y_{C A}
$$

(ii) $\beta_{C A}$

As is illustrated in Fig. 4, due to the inclination of $\mathrm{C}$ axis by the angle $\beta_{C A}$, the bottom surface generated by the machining step (d) is inclined by $2 \beta_{C A}$ around the $\mathrm{Y}$ axis from that generated by the machining step (c). In other words, we have:

$$
\phi^{1 a}=-2 \beta_{C A}
$$

(iii) $\alpha_{A Y}$

As is illustrated in Fig. 5, due to the inclination of $\mathrm{C}$ axis by $\alpha_{A Y}$ around the $\mathrm{X}$ axis, the $\mathrm{Z}$ location of bottom surfaces generated by machining steps (c) and (d) differ by the distance $2 C_{y} \alpha_{A Y}$. Notice that the $\mathrm{Z}$ location of reference bottom surfaces generated by (a) and (b) also differ by $-\left(\tilde{L}_{0}+\tilde{l}\right) \alpha_{A Y}$. Therefore, we have:

$$
\Delta H^{1 a}=\left(2 C_{y}+\tilde{L}_{0}+\tilde{l}\right) \alpha_{A Y}
$$

From Fig. 5, it can be also observed that $\alpha_{A Y}$ also affects the width of side surfaces generated by (c) and (d) as follows:

$$
\Delta L^{1 a}=-2\left(\tilde{H}+\frac{1}{2} \tilde{h}\right) \alpha_{A Y}
$$

(iv) $\beta_{A Y}, \delta y_{A Y}, \alpha_{Z Y}$

In this machining pattern, the influence of $\beta_{A Y}$ and $\delta y_{A Y}$ are identical to that of $\beta_{C A}$ and $\delta y_{C A}$, respectively. The influence of $\alpha_{Z Y}$ is the same as that of $\alpha_{A Y}$ but in the opposite direction.

In this machining pattern, all the other kinematic errors impose no or negligibly small influence on geometric errors of the finished workpiece. To summarize, the influence of kinematic errors on geometric errors of the workpiece finished by Machining Pattern 1-a can be formulated as follows:

$$
\Delta L^{1 a}=2\left(\delta y_{C A}+\delta y_{A Y}\right)-2\left(\tilde{H}+\frac{1}{2} \tilde{h}\right)\left(\alpha_{A Y}-\alpha_{Z Y}\right)-2 d_{r}
$$




$$
\begin{aligned}
\Delta H^{1 a} & =\left(2 C_{y}+\tilde{L}+\tilde{l}\right) \alpha_{A Y} \\
\phi^{1 a} & =-2\left(\beta_{A Y}+\beta_{C A}\right) \\
\theta^{1 a} & =0
\end{aligned}
$$

where $d_{r} \in \mathbb{R}$ represents an error in the actual tool radius from its nominal value. Note that the width between first-level reference steps, $\Delta L_{0}^{1 a}$, is not affected by kinematic errors, and is given by:

$$
\Delta L_{0}^{1 a}=-2 d_{r}
$$

\subsection{Machining Pattern 1-b}

Figure 6 illustrates Machining Pattern 1-b. Machining steps (a) (c) are performed toward the $\mathrm{X}$ direction with $C=-90^{\circ}$, and then the rotary table is rotated to $C=-270^{\circ}$ and perform (d). Geometric error parameters of the finished workpiece are defined analogously as in the previous machining pattern and formulated as follows:

$$
\begin{aligned}
\Delta L^{1 b} & =2\left(\delta y_{A Y}+\delta y_{C A}\right)-2\left(\tilde{H}+\frac{1}{2} \tilde{h}\right)\left(\alpha_{A Y}-\alpha_{Z Y}\right)-2 d_{r} \\
\Delta H^{1 b} & =(\tilde{L}+\tilde{l}) \alpha_{A Y}-2 C_{y}\left(\beta_{A Y}+\beta_{C A}\right) \\
\phi^{1 b} & =-2\left(\beta_{A Y}+\beta_{C A}\right) \\
\theta^{1 b} & =0
\end{aligned}
$$

Naturally, the formulations for Machining Patterns 1-a and 1-b are essentially the same. The difference in Eqs. (10) and (12) comes from the assumption that $\left|C_{y}\right| \gg\left|C_{x}\right|$.

\subsection{Machining Patterns 2- $a$ and 2-b}

Figures 7 and 8 respectively illustrate Machining Patterns 2-a and 2b. The machining procedure is analogous to Machining Patterns 1-a and 1b, except for that the machining is toward the Y-direction. Geometric error parameters of the finished workpiece are formulated as follows:

Machining Pattern 2-a:

$$
\Delta L^{2 a}=-2 \delta x_{A Y}-2\left(\tilde{H}+\frac{1}{2} \tilde{h}\right)\left(\beta_{A Y}+\beta_{C A}-\beta_{Z X}\right)-2 d_{r}
$$




$$
\begin{aligned}
\Delta H^{2 a} & =(\tilde{L}+\tilde{l})\left(\beta_{A Y}+\beta_{C A}\right)+2 C_{y} \alpha_{A Y} \\
\phi^{2 a} & =2 \alpha_{A Y} \\
\theta^{2 a} & =0
\end{aligned}
$$

Machining Pattern 2-b:

$$
\begin{aligned}
\Delta L^{2 b} & =-2 \delta x_{A Y}-2\left(\tilde{H}+\frac{1}{2} \tilde{h}\right)\left(\beta_{A Y}+\beta_{C A}-\beta_{Z X}\right)-2 d_{r} \\
\Delta H^{2 b} & =\left(\tilde{L}+\tilde{l}+2 C_{y}\right)\left(\beta_{A Y}+\beta_{C A}\right) \\
\phi^{2 b} & =2 \alpha_{A Y} \\
\theta^{2 b} & =0
\end{aligned}
$$

\subsection{Machining Pattern 3}

Figure 9 illustrates Machining Pattern 3. The machining step (c) is first performed toward $-\mathrm{X}$ direction with $C=-90^{\circ}$ and $A=-90^{\circ}$. Then, rotate the $\mathrm{C}$ axis by $-180^{\circ}$, and perform (d) toward $-\mathrm{X}$ direction. Geometric error parameters of the finished workpiece are defined analogously. In this machining pattern, note that side surfaces of the finished workpiece are machined by bottom edges of the tool, and its bottom surfaces are by side edges of the tool.

In this and all the following machining patterns, first-level reference steps are machined at $A=C=0^{\circ}$, as is shown in Fig. 7. These steps are not depicted in Fig. 9 for its simplification. Recall that the following equations contain the influence of kinematic errors on geometric errors of reference steps.

$$
\begin{aligned}
\Delta L^{3} & =-2\left(\delta y_{C A}+\delta z_{A Y}\right)+2\left(\tilde{H}+\frac{1}{2} \tilde{h}\right) \alpha_{A Y} \\
\Delta H^{3} & =(\tilde{L}+\tilde{l})\left(\beta_{A Y}+\beta_{C A}\right)+2 C_{y}\left(\beta_{C A}+\gamma_{A Y}\right) \\
\phi^{3} & =2\left(\beta_{C A}+\gamma_{A Y}\right) \\
\theta^{3} & =0
\end{aligned}
$$

\subsection{Machining Pattern 4}

Figure 10 illustrates Machining Pattern 4. The machining step (c) is first performed toward $-\mathrm{X}$ direction with $C=-90^{\circ}$ and $A=-90^{\circ}$. Then, rotate the $\mathrm{A}$ axis by $180^{\circ}$, and perform (d) toward $+\mathrm{X}$ direction. 


$$
\begin{aligned}
\Delta L^{4} & =-2 C_{y} \beta_{A Y}-2 \delta z_{A Y} \\
\Delta H^{4} & =-2 \delta y_{A Y}+(\tilde{L}+\tilde{l})\left(\alpha_{A Y}+\beta_{A Y}+\beta_{C A}-\alpha_{Z Y}\right)+2 C_{y} \gamma_{A Y} \\
\phi^{4} & =2 \gamma_{A Y} \\
\theta^{4} & =-2 \beta_{A Y}
\end{aligned}
$$

\subsection{Machining Patterns 5- $a$ and 5-b}

Figures 11(a) and 12 respectively illustrate Machining Patterns 5-a and 5-b. In Machining Pattern 5-a, the workpiece is placed at the $-Y$ location with $C=0$, while it is at the $+X$ location with $C=-90^{\circ}$ in Machining Pattern 5 -b. First, the table is tilted by $A=-45^{\circ}$ and perform the side cutting toward -X direction in both cases. Then, in Machining Patterns 5-a (Fig. 11(a)), the table is tilted to $A=45^{\circ}$ and machine toward $+\mathrm{X}$ direction as illustrated in the machining step (d). In Machining Patterns 5-b (Fig. 12), the table is rotated from $C=-90^{\circ}$ to $C=+90^{\circ}$, and machine toward $-\mathrm{X}$ direction.

Figure 11(b) illustrates the finished workpiece. The workpiece coordinate system $X_{w} Y_{w} Z_{w}$ is defined analogously. Let $S_{c}$ and $S_{d}$ denote an intersecting line of the surface generated by (c) and (d), respectively, and the $X_{w} Y_{w}$ plane at the height $Z_{w}=\tilde{H}$ from the center line of the A axis. In Machining pattern 5-a, let $L^{5 a} \in \mathbb{R}$ denote the distance between $S_{c}$ and $S_{d}$, and define $\Delta L^{5 a}:=$ $L^{5 a}-\tilde{L}$. Let $\theta^{5 a} \in \mathbb{R}$ denote the angle of $S_{c}$ to $S_{d}$ around the $Z_{w}$ axis. Geometric errors are formulated as follows:

Machining Pattern 5-a:

$$
\begin{aligned}
\Delta L^{5 a} & =2 \delta z_{A Y}+2 C_{y} \alpha_{Z Y}-2 \sqrt{2} d_{r} \\
\theta^{5 a} & =-2 \beta_{A Y}
\end{aligned}
$$

Machining Pattern 5-b:

$$
\begin{aligned}
\Delta L^{5 b}= & 2\left(\delta y_{C A}+\sqrt{2} \delta y_{A Y}+\delta z_{A Y}\right)+2\left(C_{y}-\tilde{H}\right) \alpha_{A Y}+2 \tilde{H} \alpha_{Z Y} \\
& -2 \sqrt{2} d_{r} \\
\theta^{5 b}= & -2 \alpha_{A Y}
\end{aligned}
$$

\subsection{Machining Patterns 6- $a$ and 6-b}

Figures 13 and 14 illustrate Machining Patterns 6-a and 6-b, respectively. Unlike Machining Pattern 5, the workpiece is machined by bottom edges of 
the tool. Geometric error parameters of the finished workpiece are formulated as follows:

Machining Pattern 6-a:

$$
\begin{aligned}
\Delta L^{6 a} & =-2(\sqrt{2}-1) \delta z_{A Y} \\
\theta^{6 a} & =2(\sqrt{2}-1) \beta_{A Y}
\end{aligned}
$$

Machining Pattern 6-b:

$$
\begin{aligned}
\Delta L^{6 b} & =-2(\sqrt{2}-1) \delta z_{A Y}-2 \delta y_{C A}-\left(\tilde{L}-2 C_{y}\right) \alpha_{A Y} \\
\theta^{6 b} & =-2 \alpha_{A Y}
\end{aligned}
$$

\subsection{Machining Pattern 7}

Figure 15 illustrates Machining Pattern 7. The table indexing is done in the same way as in Pattern 5 -a. The tool is fed to the $45^{\circ}$ direction from the $\mathrm{Y}$ axis, and its side edges machine the workpiece. Geometric error parameters of the finished workpiece are formulated as follows:

$$
\begin{aligned}
\Delta L^{7} & =-\sqrt{2} C_{y} \beta_{A Y}-\sqrt{2} \tilde{H}\left(\gamma_{A Y}-\gamma_{X Y}\right)+\sqrt{2} C_{y} \beta_{Z X}-2 d_{r} \\
\theta^{7} & =-\sqrt{2}\left(\beta_{A Y}-\beta_{Z X}\right)
\end{aligned}
$$

\section{Choice of machining patterns and identification of kinematic pa- rameters}

To separately identify all the kinematic errors, it is sufficient to perform Machining Patterns 1-a, 2-a, 3, and 4. In commercial five-axis machining centers, however, it is often the case that some of them cannot be performed due to a constraint on the movable range of rotary or linear axes. For example, on a typical five-axis machining center of the configuration shown in Fig. 1, the movable range of the $\mathrm{A}$ axis may be smaller than $\pm 90^{\circ}$, which makes it impossible to perform Machining Pattern 4.

Table 2 shows the sensitivity of each kinematic parameter to geometric errors of the finished workpiece for all the present machining patterns. When one of kinematic errors is set to $0.1^{\circ}$ (for angular errors) or $0.1 \mathrm{~mm}$ (for linear errors) with all the other parameters set to zero, geometric errors of the 
finished workpiece, $\Delta L^{*}, \Delta H^{*}, \theta^{*}$ and $\phi^{*}$, are computed by the formulations presented in Section 3. Nominal parameters associated with the workpiece placement and geometry are set as in Table 4. Based on this table, a set of machining patterns sufficient to separately identify all the kinematic errors must be selected. As examples, we present two sets of machining patterns, assuming the cases where (1) it is possible to index $A= \pm 90^{\circ}$, and (2) only $A=+90^{\circ} \sim-45^{\circ}$ is possible.

\subsection{Case 1}

Assuming that it is possible to index $A= \pm 90^{\circ}$, and to rotate the $\mathrm{C}$ axis by $360^{\circ}$, the minimum set of machining patterns to identify all the kinematic errors is Machining Patterns 1-a, 2-a, 3, and 4. The identification of kinematic parameters can be done, for example, in the following steps:

(1) $\alpha_{A Y}$ is identified from $\phi^{2 a}$ (Eq. (13)).

(2) $\beta_{A Y}$ and $\gamma_{A Y}$ are identified from $\theta^{4}$ and $\phi^{4}$ (Eq. (16)), respectively.

(3) $\beta_{C A}$ is identified from $\phi^{3}$ (Eq. (15)) by substituting the identified $\gamma_{A Y}$.

(4) $\delta z_{A Y}$ is identified from $\Delta L^{4}$ (Eq. (16)) by substituting the identified $\beta_{A Y}$.

(5) $\delta y_{C A}$ is identified from $\Delta L^{3}$ (Eq. (15)) by substituting the identified $\delta z_{A Y}$ and $\alpha_{A Y}$.

(6) $\delta y_{A Y}$ is identified from $\Delta L^{1 a}$ (Eq. (10)) by substituting the identified $\delta y_{C A}$ and $\alpha_{A Y}$.

(7) $\delta x_{A Y}$ is identified from $\Delta L^{2 a}$ (Eq. (13)) by substituting the identified $\beta_{A Y}$ and $\beta_{C A}$.

\subsection{Case 2}

This case assumes that it is not possible to perform Machining Pattern 4 due to the limited rotation range of the $\mathrm{A}$ axis, although all the other machining patterns can be performed.

(1) $\alpha_{A Y}$ is identified either from (i) $\phi^{2 a}$ (Eq. (13)) or (ii) $\phi^{2 b}$ (Eq. (14)). Since steps (c) and (d) in Machining Pattern 2-b are machined within the same $Y$ range (Fig. 8), the influence of the straightness error of the $\mathrm{Y}$ axis in 
the $\mathrm{Z}$ direction on $\phi^{2 b}$ is expectedly smaller than that on $\phi^{2 a}$. Therefore, it is reasonable to calculate $\alpha_{A Y}$ from $\phi^{2 b}$.

(2) $\beta_{A Y}+\beta_{C A}$ can be identified from (i) $\phi^{1 a}$ (Eq. (10)), (ii) $\phi^{1 b}$ (Eq. (12)), (iii) $\Delta H^{1 b}$ (Eq. (12)), and (iv) $\Delta H^{2 b}$ (Eq. (14)). In the same reason as in (1), the influence of the straightness error of the $\mathrm{X}$ axis on $\phi^{1 a}$ is expectedly smaller than that on $\phi^{1 b}$. We compute $\beta_{A Y}+\beta_{C A}$ by taking the mean of the estimates by i), iii) and iv).

(3) $\delta y_{A Y}+\delta y_{C A}$ can be identified from (i) $\Delta L^{1 a}$ (Eq. (10)) or (ii) $\Delta L^{1 b}$ (Eq. (12)). The positioning error of the $\mathrm{Y}$ axis directly affects $\Delta L^{1 a}$ (Fig. 2(a)), while the straightness error of the $\mathrm{X}$ axis may affect $\Delta L^{1 b}$ (Fig. 6). Here, we calculate $\delta y_{A Y}+\delta y_{C A}$ by taking the mean of the estimates by i) and ii).

(4) $\delta x_{A Y}$ can be identified from (i) $\Delta L^{2 a}$ (Eq. (13)) and (ii) $\Delta L^{2 b}$ (Eq. (14)). Similarly as in (3), we calculate $\delta x_{A Y}$ by taking their mean.

(5) $\beta_{A Y}$ can be identified from (i) $\theta^{6 a}$ (Eq. (19)), (ii) $\theta^{5 a}$ (Eq. (17)), and (iii) $\theta^{7}$ (Eq. (21)). We calculate $\beta_{A Y}$ by taking their mean. $\beta_{C A}$ is also calculated from (2).

(6) $\gamma_{A Y}$ is identified from $\phi^{3}$ (Eq. (15)).

(7) $\delta z_{A Y}$ is identified from $\Delta L^{6 a}$ (Eq. (19)).

(8) $\delta y_{C A}$ can be identified from (i) $\Delta L^{3}$ (Eq. (15)) and (ii) $\Delta L^{6 b}$ (Eq. (20)). We calculate $\delta y_{C A}$ by taking their mean. $\delta y_{A Y}$ is calculated from (3).

\section{Experimental Case Study}

Machining tests presented in this paper are experimentally performed on a commercial five-axis machining center to identify its kinematic errors. Kinematic errors are also identified by applying ball bar measurements presented by Tsutsumi and Saito [5] for the comparison.

A commercial machining center of the configuration shown in Fig. 1 is used in experiments. Major machining conditions are summarized in Table 3. Assuming Case 2 in Section 4.2, all the machining patterns are performed except for Machining Pattern 4. Four patterns, Machining Patterns 1-a to 2-b are machined on Workpiece \#1 shown in Fig. 16. Six patterns, Machining 
Patterns 3 to 6-b, are machined on Workpiece \#2 shown in Fig. 17. Table 4 shows nominal geometric parameters of the workpieces defined in Section 3.

Geometric errors of finished workpieces are measured by using a coordinate measuring machine (CMM), Leitz PMM866, of the measurement uncertainty $E=(0.5+L / 600) \mu \mathrm{m}$, where $L$ represents the measurement distance. Due to the limitation in paper length, only a part of measured error profiles will be shown. Figure 18 shows measured error profiles of the steps by Machining Pattern 1-b. In Fig. 18(a), at measurement points on side surfaces with an interval of $5 \mathrm{~mm}$, an error in the $X_{w}$-direction from the reference location is plotted. Dashed lines represent their least squares fit lines. In Fig. 18(b), error profiles of bottom surfaces in the $Z_{w}$ direction are plotted similarly. It can be clearly observed in Fig. 18(a) that the mean distance of two profiles has an error from its reference value by $\Delta L^{1 b}=-17.8 \mu \mathrm{m}$. Their parallelity error is also observed $\left(\theta^{1 b}=-1.3 \mu \mathrm{m} / 81.0 \mathrm{~mm}\right)$. In Fig. 18(b), the mean height error of two profiles is $H^{1 b}=-9.9 \mu \mathrm{m}$, and their parallelity error, $\phi^{1 b}=4.5 \mu \mathrm{m} / 81.0$ $\mathrm{mm}$, is relatively large. These errors are clearly caused by the machine's kinematic errors. Fig. 19 similarly shows measured error profiles of the steps by Machining Pattern 2-a. On Workpiece \#2, Fig. 20 shows measured error profiles of surfaces by Machining Pattern 3.

Tables 5 and 6 summarizes measured geometric error parameters on Workpieces $\# 1$ and $\# 2$, respectively. Note that $\Delta L_{0}^{x}$ and $\Delta L_{0}^{y}$ in Table 6 represent the measured width between reference surfaces in $X_{w}$ and $Y_{w}$ directions, respectively.

As has been stated in Section 4, squareness errors of linear axes, $\gamma_{Y X}$, $\alpha_{Z Y}$, and $\beta_{Z X}$, were independently measured by using the ball bar [19] as shown in Table 7. By following the procedure in Section 4.2, kinematic errors associated with rotary axes are identified from Table 5 and 6. Table 8 ("Estimates by machining tests") summarizes identified kinematic errors.

For the comparison, kinematic errors are also estimated by applying ball bar measurements $[5,12]$. Table 8 also shows these estimates ("Estimates by ball bar method"). Since linear errors, $\delta x_{A Y}, \delta y_{A Y}$, and $\delta z_{A Y}$, are dependent on the tool length or the origin of workpiece coordinates, they are omitted in 
Table 8.

It must be first noted that the identified $\delta z_{A Y}$ is significantly larger than other estimates. This may be caused by our error in experiments with the measurement of tool length. Significantly larger error in $\Delta L^{3}, \Delta L^{5 a}, \Delta L^{5 b}$, $\Delta L^{6 a}, \Delta L^{6 b}$ is mostly caused by this. By comparing estimates by machining tests and ball bar measurements, it can be observed that they roughly match, in that $\alpha_{A Y}$ and $\delta y_{C A}$ are significantly smaller than other kinematic errors, and that the signs of $\beta_{A Y}, \gamma_{A Y}$, and $\beta_{C A}$ are the same. The values of the estimated $\beta_{A Y}, \gamma_{A Y}$, and $\beta_{C A}$ are, however, about two to three times smaller than the estimates by ball bar measurements. As has been discussed in [12], ball bar measurements [5] are also influenced by motion errors of linear axes. Since the identification of kinematic errors ignore their influence, it may cause significant identification error.

It is also to be noted that machining conditions must be chosen such that the influence of machining process on the workpiece's geometric accuracy becomes sufficiently small. In this experiment, as has been shown in Table 3, all the finishing processes are done by the same path as in semi-finishing, such that the influence of tool deformation caused by cutting force is minimized. The feedrate must be chosen sufficiently small such that the theoretical surface error, or the influence of tool run-out, becomes sufficiently small.

\section{Discussion}

As has been discussed in Section 1, the estimation method of kinematic errors based on ball bar measurements [5] is accepted by machine tool builders to some extent. To conclude this paper, this section discusses potential advantages of the proposed machining tests over ball bar measurements.

(1) For typical machine tool users, machining tests can be more intuitively understood to evaluate the machine's accuracy.

(2) The measurement range in a ball bar measurement is limited by the length of the bar. The shortest commercially available device has the nominal length of $100 \mathrm{~mm}$ [20]. For small-sized five-axis machining centers, some of ball bar measurements in [5] may not be possible due to this limitation. The 
present machining tests can be performed over the entire travel range, and thus can be applied to any small-sized machines. For large-sized five-axis machines, the present scheme is also advantageous in that it can evaluate motion errors over the entire workspace.

(3) Many ball bar measurements in [5] are performed by synchronously driving a rotary axis and two linear axes, while present machining tests are mostly performed by driving only one linear axis during the cutting. Therefore, the influence of error sources other than kinematic errors, such as dynamic error of rotary axes, is minimized.

(4) Ball bar measurements must be set up and operated by an experienced operator. For present machining tests, by replacing the CMM measurement with an on-the-machine measurement using a touch probe or a displacement sensor installed to the machine's spindle, full automation of entire machining and measurement processes is potentially possible. The automation of calibration process is important for the application to mass production.

\section{Conclusion}

This paper proposed machining tests for a five-axis machine tool such that its kinematic errors can be separately identified by evaluating the geometric error of finished workpieces. In each machining pattern, a simple straight side cutting using a straight end mill is performed. Experimental results demonstrate that the influence of kinematic errors can be observed in a very comprehensive manner on error profiles of finished workpieces.

This paper only targets the identification of kinematic errors, as the most fundamental error sources of a five-axis machine tool. The extension of the present tests to the diagnosis of other major error sources of a five-axis machine tool, such as the positioning error of rotary axes, as well as the extension of its application to other types of multi-axis machine tools such as a lathe-type multi-task machine tool, will be studied in our future research. 


\section{Acknowledgement}

This research was funded in part by JSPS Grant-in-Aid for Scientific Research (\#19760087). 


\section{References}

[1] IS0 10791 series, Test conditions for machining centres, International Organization for Standardization, 1998.

[2] Tsutsumi, M., Ihara, Y., Saito, A., Mishima, N., Ibaraki, S., Yamamoto, M., Kobayashi, M., Yonetani, T., Standardization of testing methods for kinematic motion of five-axis machining centers - Draft proposal for ISO standard -, Proc. of the 7th Manufacturing and Machine Tool Conference, 2008; 95-96 (in Japanese).

[3] Kakino, Y., Ihara, T., Sato, H., Otsubo, H., A Study on the motion accuracy of NC machine tools (7th report) -Measurement of motion accuracy of 5-axis machine by DBB tests-, Journal of Japan Society for Precision Engineering, 1994; 60 (5); 718-723 (in Japanese).

[4] Abbaszaheh-Mir, Y., Mayer, J. R. R., Clotier, G., Fortin, C., Theory and simulation for the identification of the link geometric errors for a five-axis machine tool using a telescoping magnetic ball-bar, International Journal of Production Research, 2002; 40(18); 4781-4797.

[5] Tsutsumi, M., Saito, A., Identification and compensation of systematic deviations particular to 5-axis machining centers, International Journal of Machine Tools and Manufacture, 2003; 43; 771-780.

[6] Tsutsumi, M., Saito, A., Identification of angular and positional deviations inherent to 5 -axis machining centers with a tilting-rotary table by simultaneous four-axis control movement, International Journal of Machine Tools and Manufacture, 2004; 44; 1333-1342.

[7] Bringmann, B., Knapp, W., Model-based Chase-the-Ball' calibration of a 5-axis machining center, Annals of the CIRP, 2006; 55(1); 531-534.

[8] ISO 10791-7 Test Conditions for Machining Centres - Part 7: Accuracy of a Finished Test Piece, ISO (International Organization for Standardization), 1998.

[9] NAS 979: Uniform cutting test - NAS series, metal cutting equipment specifications, $1969 ; 34-37$.

[10] Matsushita, T., The accuracy of cone frustum machined by five-axis machining center with titling table, Proc. of 2007 JSPE Spring Annual Conference, 2007; 187-188 (in Japanese).

[11] Yumiza, D., Yoshinobu, S., Tsutsumi, M., Utsumi, K., Ihara, Y., Measurement method for motion accuracies of 5 -axis machining centers -2 nd report, influence 
of geometric deviations on finished cone frustums -, Proceedings. of 2007 JSPE Spring Annual Conference, 2007; 191-192 (in Japanese).

[12] Uddin, M. S., Ibaraki, S., Matsubara, A., Matsushita, T., Prediction and Compensation of Machining Geometric Errors of 5-axis Machining Centers with Kinematic Errors, Precision Engineering, 2009; 33(2); 194-201.

[13] Ohashi, T., Morimoto, Y., Ichida, Y., Sato, R., Ugamochi, K., Akaba, T., Study on Accuracy Compensation of Machining Center Based on Measurement Results of Workpiece (3rd Report) - Accuracy Compensation of 5-axis Controlled Machining Center -, Proc. of 2006 JSPE Spring Annual Conference, 2006; 147148 (in Japanese).

[14] http://www.ncg.de

[15] JIS B 6310: Industrial automation systems and integration - Numerical control of machines - coordinate system and motion nomenclature, Japanese Standard Association, 2003

[16] Inasaki, I., Kishinami, K., Sakamoto, S., Sugimura, N., Takeuchi, Y., Tanaka, F., Shaper generation theory of machine tools - its basis and applications, Yokendo, Tokyo, 1997. pp. 95-103 (in Japanese)

[17] Srivastava, A. K., Veldhuis, S. C., Elbestawi, M. A., Modeling geometric and thermal errors in a five-axis CNC machine tool, International Journal of Machine Tools and Manufacture, 1994; 35(9); 1321-1337.

[18] Soons, J. A., Theuws, F.C., Schllekens, P.H., Modeling the errors of multi-axis machines: a general methodology, Precision Engineering, 1992; 14(1); 5-19.

[19] Kakino, Y., Ihara, Y., Shinohara, A., Accuracy Inspection of NC Machine Tools by Double Ball Bar Method, Hanser Publishers, 1993.

[20] QC10 ballbar brochure, Renishaw plc, 2008. 


\section{List of Tables}

$1 \quad$ Kinematic errors.

2 Sensitivity of kinematic errors to geometric errors of the finished workpiece.

$3 \quad$ Major machining conditions.

4 Nominal geometric parameters of the workpieces.

$5 \quad$ Measured geometric errors of Workpiece \#1.

6 Measured geometric errors of Workpiece \#2.

$7 \quad$ Measured squareness errors of linear axes.

8 Kinematic errors estimated from geometric errors of finished workpieces, in comparison with the estimates by ball bar measurements $[5,12]$.

\section{List of Figures}

1 The configuration of a five-axis machine tool considered in this paper.

(a) Machining procedure. 36

(b) Finished workpiece geometry. 36

(c) Intersecting lines of side surfaces and the $X_{w} Y_{w}$ plane. $\quad 36$

(d) Intersecting lines of bottom surfaces and the $X_{w} Z_{w}$ plane. 
3 The influence of $\delta y_{C A}$ on the geometric error of the finished workpiece.

(a) With $\delta y_{C A}=0$.

(b) With $\delta y_{C A}>0$.

4 The influence of $\beta_{C A}$ on the geometric error of the finished workpiece.

(a) At machining step (c).

(b) At machining step (d).

5 The influence of $\alpha_{A Y}$ on the geometric error of the finished workpiece.

$6 \quad$ Machining Pattern 1-b.

$7 \quad$ Machining Pattern 2-a.

$8 \quad$ Machining Pattern 2-b.

$9 \quad$ Machining pattern 3.

10 Machining pattern 4.

11 Machining pattern 5-a.

(a) Machining procedure.

(b) Finished workpiece geometry.

12 Machining pattern 5-b.

13 Machining pattern 6-a.

14 Machining pattern 6-b. 
15 Machining pattern 7.

16 The geometry of the finished Workpiece \#1.

17 The geometry of the finished Workpiece \#2.

18 Measured error profiles of workpiece surfaces machined by Machining Pattern 1-b.

(a) Geometric error of side surfaces in the $X_{w}$ direction from their reference position.

(b) Geometric error of bottom surfaces in the $Z_{w}$ direction from their reference position.

19 Measured error profiles of workpiece surfaces machined by Machining Pattern 2-a.

(a) Geometric error of side surfaces in the $X_{w}$ direction from their reference position.

(b) Geometric error of bottom surfaces in the $Z_{w}$ direction from their reference position.

20 Measured error profiles of workpiece surfaces machined by Machining Pattern 3.

(a) Geometric error of side surfaces in the $X_{w}$ direction from their reference position.

(b) Geometric error of bottom surfaces in the $Z_{w}$ direction from their reference position. 
Table 1

Kinematic errors.

\begin{tabular}{l|l}
\hline$\alpha_{A Y}$ & angular error of A-axis about X-axis with respect to Y-axis. \\
$\beta_{A Y}$ & angular error of A-axis about Y-axis with respect to Y-axis. \\
$\gamma_{A Y}$ & angular error of A-axis about Z-axis with respect to Y-axis. \\
$\beta_{C A}$ & angular error of the center line of C-axis about Y-axis with respect to that of A-axis. \\
$\delta x_{A Y}$ & linear shift of A-axis in X-direction with respect to Y-axis. \\
$\delta y_{A Y}$ & linear shift of A-axis in Y-direction with respect to Y-axis. \\
$\delta z_{A Y}$ & linear shift of A-axis in Z-direction with respect to Y-axis. \\
$\delta y_{C A}$ & linear shift of C-axis in Y-direction with respect to A-axis. \\
$\gamma_{Y X}$ & squareness error of Y-axis with respect to X-axis. \\
$\alpha_{Z Y}$ & squareness error of Z-axis with respect to Y-axis. \\
$\beta_{Z X}$ & squareness error of Z-axis with respect to X-axis. \\
\hline
\end{tabular}


Table 2

Sensitivity of kinematic errors to geometric errors of the finished workpiece.

\begin{tabular}{|c|c|c|c|c|c|c|c|c|c|c|c|c|}
\hline $\begin{array}{l}\text { Machining } \\
\text { Pattern }\end{array}$ & $\begin{array}{l}\text { Work. } \\
\text { Error }\end{array}$ & $\alpha_{A Y}$ & $\beta_{A Y}$ & $\beta_{C A}$ & $\gamma_{A Y}$ & $\delta x_{A Y}$ & $\delta y_{A Y}$ & $\delta y_{C A}$ & $\delta z_{A Y}$ & $\gamma_{X Y}$ & $\alpha_{Z Y}$ & $\beta_{Z X}$ \\
\hline \multirow[t]{4}{*}{$1-\mathrm{a}$} & $\Delta L^{1 a}$ & -0.61 & - & - & - & - & +0.2 & +0.2 & - & - & \begin{tabular}{|l|}
+0.61 \\
\end{tabular} & - \\
\hline & $\theta^{1 a}$ & $\begin{array}{lll}- & \\
\end{array}$ & - & - & - & - & - & - & $\begin{array}{ll}- \\
-\end{array}$ & - & - & - \\
\hline & $\Delta H^{1 a}$ & -0.22 & - & - & - & - & - & - & - & - & - & - \\
\hline & $\phi^{1 a}$ & - & $\begin{array}{l}-0.20 \\
\end{array}$ & $\begin{array}{l}-0.20 \\
\end{array}$ & $\begin{array}{l}- \\
-\end{array}$ & - & - & - & - & - & - & - \\
\hline \multirow[t]{4}{*}{$1-b$} & $\Delta L^{16}$ & -0.57 & - & - & - & - & +0.2 & +0.2 & - & - & +0.57 & - \\
\hline & $\theta^{16}$ & - & - & - & - & - & - & - & - & - & - & - \\
\hline & $\Delta H^{16}$ & -0.16 & +0.34 & +0.34 & - & - & - & - & - & - & - & - \\
\hline & $\phi^{16}$ & - & -0.20 & -0.20 & - & - & - & - & - & - & - & - \\
\hline \multirow[t]{4}{*}{$2-\mathrm{a}$} & $\Delta L^{2 a}$ & - & -0.61 & -0.61 & - & -0.2 & - & - & - & - & - & +0.61 \\
\hline & $\theta^{2 a}$ & $\begin{array}{l}- \\
-\end{array}$ & - & - & - & - & - & - & - & - & - & - \\
\hline & $\Delta H^{2 a}$ & $\begin{array}{l}-0.34 \\
\end{array}$ & +0.10 & +0.10 & $\begin{array}{l}- \\
-\end{array}$ & - & - & - & - & - & - & - \\
\hline & $\phi^{2 a}$ & +0.2 & - & - & - & - & - & - & - & - & - & - \\
\hline \multirow[t]{4}{*}{$2-b$} & $\Delta L^{2 b}$ & - & -0.57 & -0.57 & - & -0.2 & - & - & - & - & - & +0.57 \\
\hline & $\theta^{2 b}$ & - & - & - & - & - & - & - & - & - & - & - \\
\hline & $\Delta H^{2 b}$ & - & -0.19 & -0.19 & - & - & - & - & - & - & - & - \\
\hline & $\phi^{2 b}$ & +0.27 & - & - & - & - & - & - & - & - & - & - \\
\hline \multirow[t]{4}{*}{3} & $\Delta L^{3}$ & +0.50 & - & - & - & - & - & \begin{tabular}{|l|}
-0.2 \\
\end{tabular} & \begin{tabular}{|l|}
-0.2 \\
\end{tabular} & - & - & - \\
\hline & $\theta^{3}$ & - & - & - & - & - & - & - & - & - & - & - \\
\hline & $\Delta H^{3}$ & - & +0.16 & -0.18 & \begin{tabular}{|l|}
-0.34 \\
\end{tabular} & - & - & - & - & - & - & - \\
\hline & $\phi^{3}$ & - & - & $\begin{array}{l}+0.2 \\
\end{array}$ & +0.2 & - & - & - & - & - & - & - \\
\hline \multirow[t]{4}{*}{4} & $\Delta L^{4}$ & - & +0.34 & - & - & - & - & - & \begin{tabular}{|l|}
-0.2 \\
\end{tabular} & - & - & - \\
\hline & $\theta^{4}$ & $\begin{array}{lll}- & \end{array}$ & -0.2 & - & $\begin{array}{lll}- & \end{array}$ & - & - & - & - & - & - & - \\
\hline & $\Delta H^{4}$ & +0.16 & +0.16 & +0.16 & \begin{tabular}{|l|}
-0.34 \\
\end{tabular} & - & -0.2 & - & - & - & \begin{tabular}{|l|}
-0.16 \\
\end{tabular} & - \\
\hline & $\phi^{4}$ & - & - & - & +0.2 & - & - & - & - & - & - & - \\
\hline \multirow[t]{2}{*}{5 -a } & $\Delta L^{5 a}$ & - & - & - & - & - & - & - & +0.2 & - & \begin{tabular}{|l|}
-0.34 \\
\end{tabular} & - \\
\hline & $\theta^{5 a}$ & - & -0.2 & - & - & - & - & - & - & - & - & - \\
\hline \multirow[t]{2}{*}{$5-b$} & $\Delta L^{5 b}$ & -0.89 & - & - & - & - & +0.28 & +0.2 & +0.2 & - & +0.55 & - \\
\hline & $\theta^{5 b}$ & -0.12 & - & - & - & - & - & - & - & - & - & - \\
\hline \multirow[t]{2}{*}{$6-\mathrm{a}$} & $\Delta L^{6 a}$ & - & - & - & - & - & - & - & -0.08 & - & - & - \\
\hline & $\theta^{6 a}$ & $\begin{array}{lll}- & \\
\end{array}$ & +0.03 & $\begin{array}{ll}- \\
-\end{array}$ & $\begin{array}{lll}- \\
-\end{array}$ & - & - & - & - & - & - & - \\
\hline \multirow[t]{2}{*}{$6-\mathrm{b}$} & $\Delta L^{66}$ & +0.14 & - & - & - & - & - & -0.2 & -0.08 & - & - & - \\
\hline & $\theta^{6 b}$ & -0.2 & - & - & - & - & - & - & - & - & $\begin{array}{ll}- \\
-\end{array}$ & - \\
\hline \multirow[t]{2}{*}{7} & $\Delta L^{7}$ & - & +0.24 & $\begin{array}{lll}- & \\
\end{array}$ & \begin{tabular}{|l|}
-0.38 \\
\end{tabular} & - & $\begin{array}{lll}- & -1\end{array}$ & $\begin{array}{lll}- & \end{array}$ & - & +0.38 & - & -0.24 \\
\hline & $\theta^{\top}$ & - & -0.14 & - & - & - & - & - & - & - & - & +0.14 \\
\hline
\end{tabular}

$\Delta L^{*}$ and $\Delta H^{*}$ are in millimeter. $\theta^{*}$ and $\phi^{*}$ are in degree. "-" represents that the effect is zero or negligibly small. 
Table 3

Major machining conditions.

\begin{tabular}{l|l}
\hline Tool & $\begin{array}{l}\text { a sintered carbide straight end } \\
\text { mill, } \phi 20 \mathrm{~mm}, \text { two flutes }\end{array}$ \\
\hline Workpiece & Aluminum alloy, JIS A5052 \\
\hline Spindle speed & $5,000 \mathrm{~min}^{-1}$ \\
\hline Feedrate & $1,000 \mathrm{~mm} / \mathrm{min}$ \\
\hline Coolant & Walter-solvent emersion \\
\hline Radial depth of cut & $\begin{array}{l}0.1 \mathrm{~mm} \text { for semi-finishing, and } \\
\text { then finishing at the same path. }\end{array}$ \\
\hline
\end{tabular}


Table 4

Nominal geometric parameters of the workpieces.

(a) Workpiece \#1:

\begin{tabular}{l|l|l}
\hline Machining Pattern & $\tilde{H} \mathrm{~mm}$ & $\tilde{L} \mathrm{~mm}$ \\
\hline 1 -a & 175.4 & 56.8 \\
\hline 1 -b & 165.4 & 76.8 \\
\hline 2-a & 165.4 & 81.0 \\
\hline 2-b & 175.4 & 61.0 \\
\hline Common parameters & $\left(C_{x}, C_{y}\right)=$ \\
& $(3.941,-96.376) \mathrm{mm}$, \\
& $\tilde{h}=5 \mathrm{~mm}, \tilde{l}=5 \mathrm{~mm}$ \\
\hline
\end{tabular}

(b) Workpiece \#2:

\begin{tabular}{l|l|l}
\hline Machining Pattern & $\tilde{H} \mathrm{~mm}$ & $\tilde{L} \mathrm{~mm}$ \\
\hline 3 & 143.9 & 86.5 \\
\hline $5-\mathrm{a}$ & 179.2 & 37.5 \\
\hline 5 -b & 179.2 & 33.0 \\
\hline 6 -a & 169.2 & 57.5 \\
\hline 6 -b & 169.2 & 53.0 \\
\hline 7 & 160.9 & 76.5 \\
\hline Common parameters & $\left(C_{x}, C_{y}\right)=$ \\
& $(3.677,-97.150) \mathrm{mm}$ \\
\hline
\end{tabular}


Table 5

Measured geometric errors of Workpiece \#1.

\begin{tabular}{|c|c|c|}
\hline $\begin{array}{l}\text { Machining } \\
\text { Pattern }\end{array}$ & Error & $\begin{array}{l}\text { Measured } \\
\text { value }\end{array}$ \\
\hline \multirow{5}{*}{$1-\mathrm{a}$} & $\Delta L^{1 a}$ & $-24.6 \mu \mathrm{m}$ \\
\hline & $\Delta H^{1 a}$ & $-1.5 \mu \mathrm{m}$ \\
\hline & $\theta^{1 a}$ & $\begin{array}{l}-0.2 \mu \mathrm{m} / 56.8 \mathrm{~mm} \\
\left(-0.2 \times 10^{-3} \text { deg. }\right)\end{array}$ \\
\hline & $\phi^{1 a}$ & $\begin{array}{l}+1.4 \mu \mathrm{m} / 56.8 \mathrm{~mm} \\
\left(+1.4 \times 10^{-3} \text { deg. }\right)\end{array}$ \\
\hline & $\Delta L_{0}^{1 a}$ & $-27.0 \mu \mathrm{m}$ \\
\hline \multirow{5}{*}{$1-b$} & $\Delta L^{1 b}$ & $-17.8 \mu \mathrm{m}$ \\
\hline & $\Delta H^{1 b}$ & $+9.9 \mu \mathrm{m}$ \\
\hline & $\theta^{1 b}$ & $\begin{array}{l}-1.3 \mu \mathrm{m} / 81.0 \mathrm{~mm} \\
\left(-0.9 \times 10^{-3} \text { deg. }\right)\end{array}$ \\
\hline & $\phi^{1 b}$ & $\begin{array}{l}+4.5 \mu \mathrm{m} / 81.0 \mathrm{~mm} \\
\left(+3.2 \times 10^{-3} \text { deg. }\right)\end{array}$ \\
\hline & $\Delta L_{0}^{16}$ & $-23.2 \mu \mathrm{m}$ \\
\hline \multirow{5}{*}{$2-\mathrm{a}$} & $\Delta L^{2 a}$ & $-20.7 \mu \mathrm{m}$ \\
\hline & $\Delta H^{2 a}$ & $-4.4 \mu \mathrm{m}$ \\
\hline & $\theta^{2 a}$ & $\begin{array}{l}-0.2 \mu \mathrm{m} / 61.0 \mathrm{~mm} \\
\left(-0.2 \times 10^{-3} \text { deg. }\right)\end{array}$ \\
\hline & $\phi^{2 a}$ & $\begin{array}{l}-0.1 \mu \mathrm{m} / 61.0 \mathrm{~mm} \\
\left(-0.1 \times 10^{-3} \text { deg. }\right)\end{array}$ \\
\hline & $\Delta L_{0}^{2 a}$ & $-24.4 \mu \mathrm{m}$ \\
\hline \multirow{5}{*}{$2-\mathrm{b}$} & $\Delta L^{2 b}$ & $-23.4 \mu \mathrm{m}$ \\
\hline & $\Delta H^{2 b}$ & $+1.9 \mu \mathrm{m}$ \\
\hline & $\theta^{2 b}$ & $\begin{array}{l}-1.2 \mu \mathrm{m} / 76.8 \mathrm{~mm} \\
\left(-0.9 \times 10^{-3} \text { deg. }\right)\end{array}$ \\
\hline & $\phi^{2 b}$ & $\begin{array}{l}-0.2 \mu \mathrm{m} / 76.8 \mathrm{~mm} \\
\left(-0.1 \times 10^{-3} \text { deg. }\right)\end{array}$ \\
\hline & $\Delta L_{0}^{2 b}$ & $-25.5 \mu \mathrm{m}$ \\
\hline
\end{tabular}


Table 6

Measured geometric errors of Workpiece \#2.

\begin{tabular}{|c|c|c|}
\hline $\begin{array}{l}\text { Machining } \\
\text { Pattern }\end{array}$ & Error & $\begin{array}{l}\text { Measured } \\
\text { value }\end{array}$ \\
\hline \multirow{2}{*}{$\begin{array}{l}\text { Reference } \\
\text { steps }\end{array}$} & $\Delta L_{0}^{x}$ & $-26.2 \mu \mathrm{m}$ \\
\hline & $\Delta L_{0}^{y}$ & $-28.0 \mu \mathrm{m}$ \\
\hline \multirow{4}{*}{3} & $\Delta L^{3}$ & $+477.6 \mu \mathrm{m}$ \\
\hline & $\Delta H^{3}$ & $+10.6 \mu \mathrm{m}$ \\
\hline & $\theta^{3}$ & $\begin{array}{l}-2.0 \mu \mathrm{m} / 91.0 \mathrm{~mm} \\
\left(-1.3 \times 10^{-3} \text { deg. }\right)\end{array}$ \\
\hline & $\phi^{3}$ & $\begin{array}{l}-7.9 \mu \mathrm{m} / 91.0 \mathrm{~mm} \\
\left(-5.0 \times 10^{-3} \text { deg. }\right)\end{array}$ \\
\hline \multirow[b]{2}{*}{$5-\mathrm{a}$} & $\Delta L^{5 a}$ & $-464.2 \mu \mathrm{m}$ \\
\hline & $\theta^{5 a}$ & $\begin{array}{l}+2.1 \mu \mathrm{m} / 29.4 \mathrm{~mm} \\
\left(+4.1 \times 10^{-3} \text { deg. }\right)\end{array}$ \\
\hline \multirow[b]{2}{*}{$5-\mathrm{b}$} & $\Delta L^{5 b}$ & $-485.5 \mu \mathrm{m}$ \\
\hline & $\theta^{5 b}$ & $\begin{array}{l}+1.1 \mu \mathrm{m} / 33.9 \mathrm{~mm} \\
\left(+1.9 \times 10^{-3} \text { deg. }\right)\end{array}$ \\
\hline \multirow[b]{2}{*}{$6-\mathrm{a}$} & $\Delta L^{6 a}$ & $+187.0 \mu \mathrm{m}$ \\
\hline & $\theta^{6 a}$ & $\begin{array}{l}-1.8 \mu \mathrm{m} / 49.4 \mathrm{~mm} \\
\left(-2.1 \times 10^{-3} \text { deg. }\right)\end{array}$ \\
\hline \multirow[b]{2}{*}{$6-b$} & $\Delta L^{6 b}$ & $+202.6 \mu \mathrm{m}$ \\
\hline & $\theta^{6 b}$ & $\begin{array}{l}+0.7 \mu \mathrm{m} / 53.9 \mathrm{~mm} \\
\left(+0.7 \times 10^{-3} \text { deg. }\right)\end{array}$ \\
\hline \multirow[b]{2}{*}{7} & $\Delta L^{7}$ & $-26.4 \mu \mathrm{m}$ \\
\hline & $\theta^{7}$ & $\begin{array}{l}+13.4 \mu \mathrm{m} / 81.0 \mathrm{~mm} \\
\left(+9.5 \times 10^{-3} \text { deg. }\right)\end{array}$ \\
\hline
\end{tabular}


Table 7

Measured squareness errors of linear axes.

\begin{tabular}{c|c}
\hline$\gamma_{Y X}$ & $-0.0034^{\circ}$ \\
\hline$\alpha_{Z Y}$ & $-0.0054^{\circ}$ \\
\hline$\beta_{Z X}$ & $+0.0037^{\circ}$ \\
\hline
\end{tabular}


Table 8

Kinematic errors estimated from geometric errors of finished workpieces, in comparison with the estimates by ball bar measurements [5,12].

\begin{tabular}{l|l|l}
\hline Kinematic error & $\begin{array}{l}\text { Estimates by } \\
\text { machining tests }\end{array}$ & $\begin{array}{l}\text { Estimates by } \\
\text { ball bar measurements }\end{array}$ \\
\hline$\alpha_{A Y}$ & $-0.0001^{\circ}$ & $0.0001^{\circ}$ \\
\hline$\beta_{A Y}$ & $-0.0025^{\circ}$ & $-0.0071^{\circ}$ \\
\hline$\gamma_{A Y}$ & $-0.0034^{\circ}$ & $-0.0081^{\circ}$ \\
\hline$\beta_{C A}$ & $+0.0020^{\circ}$ & $+0.0060^{\circ}$ \\
\hline$\delta x_{A Y}$ & $+0.014 \mathrm{~mm}$ & - \\
\hline$\delta y_{A Y}$ & $+0.018 \mathrm{~mm}$ & - \\
\hline$\delta z_{A Y}$ & $-0.226 \mathrm{~mm}$ & - \\
\hline$\delta y_{C A}$ & $-0.001 \mathrm{~mm}$ & $+0.003 \mathrm{~mm}$ \\
\hline
\end{tabular}




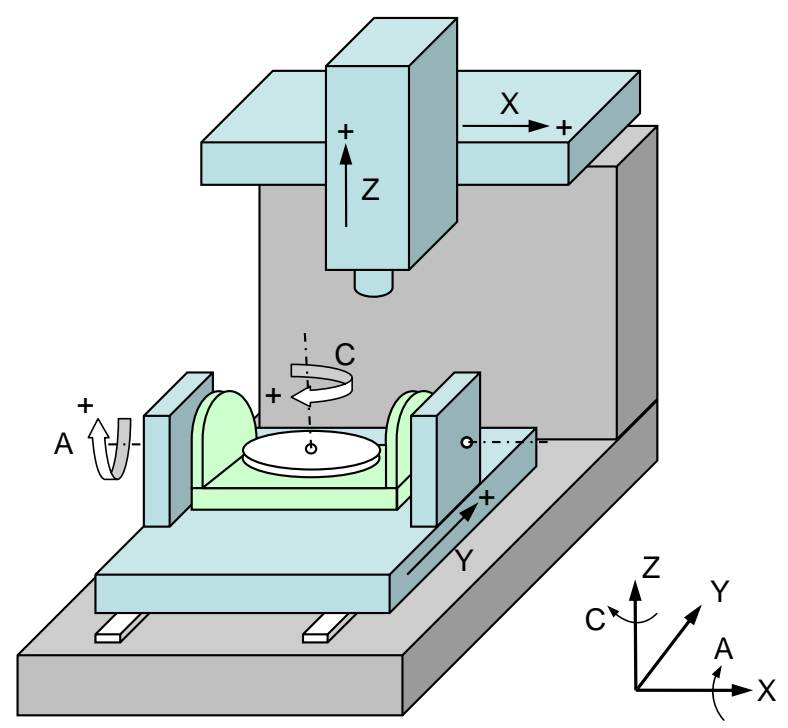

Fig. 1. The configuration of a five-axis machine tool considered in this paper. 


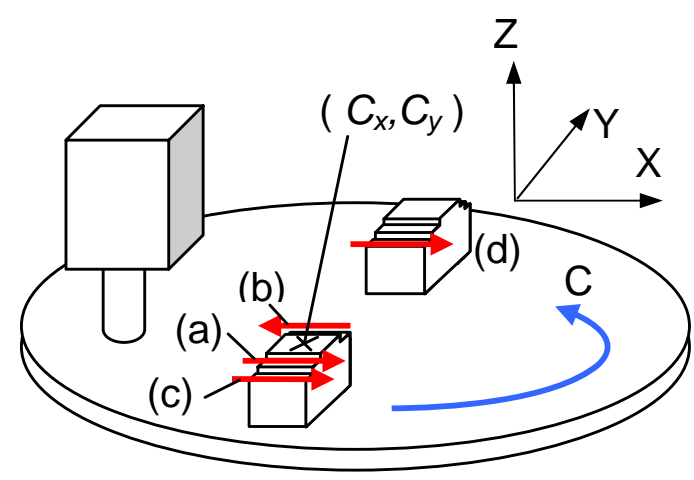

(a) Machining procedure. 
(b)

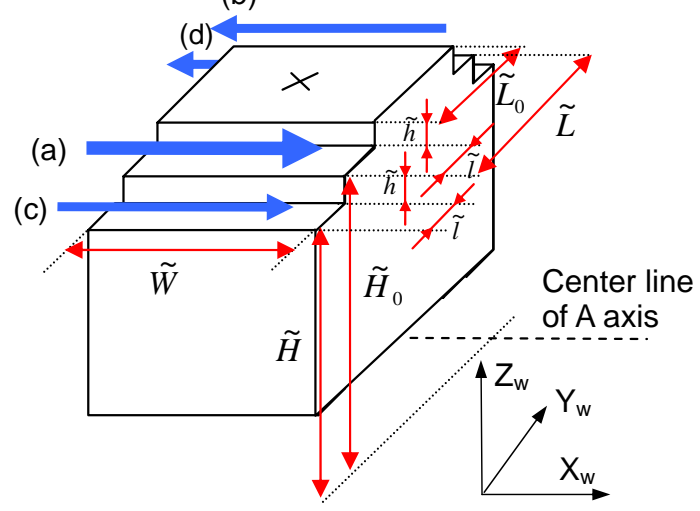

(b) Finished workpiece geometry. 


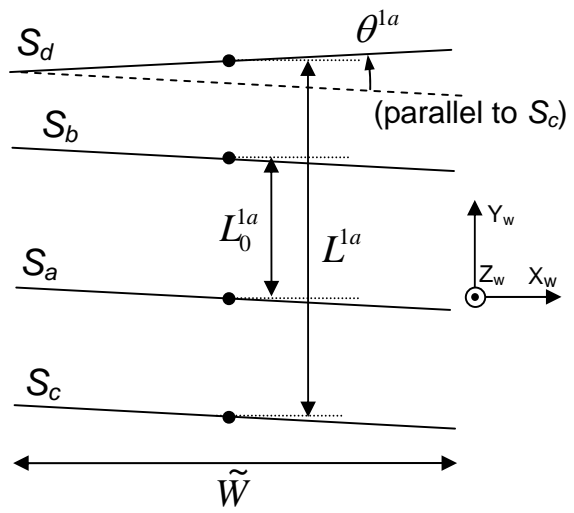

(c) Intersecting lines of side surfaces and the $X_{w} Y_{w}$ plane. 


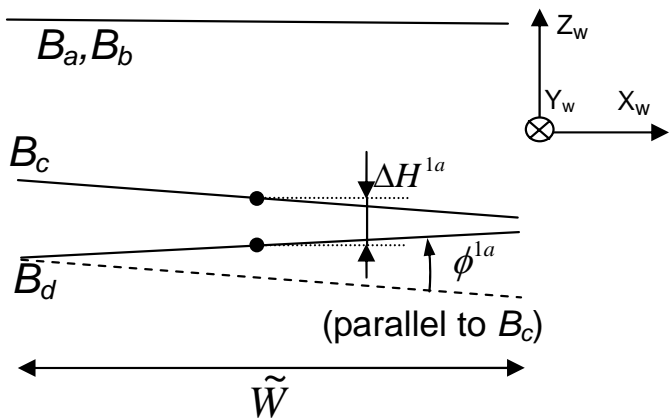

(d) Intersecting lines of bottom surfaces and the $X_{w} Z_{w}$ plane.

Fig. 2. Machining Pattern 1-a. 


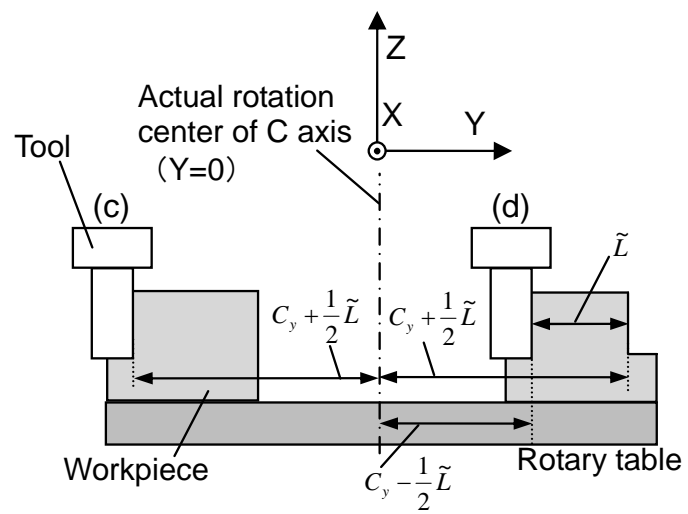

(a) With $\delta y_{C A}=0$. 


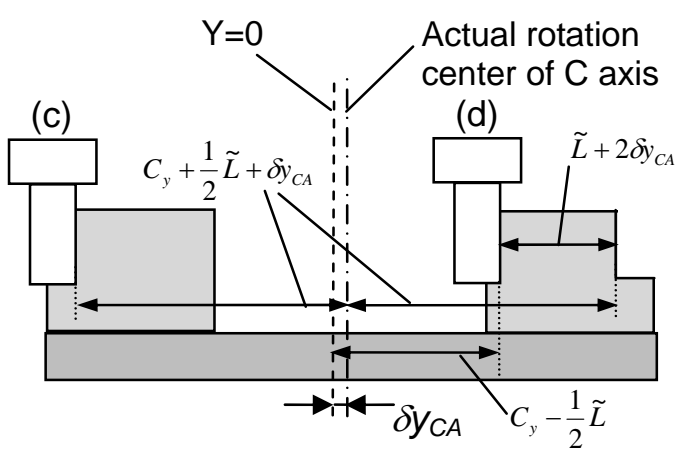

(b) With $\delta y_{C A}>0$.

Fig. 3. The influence of $\delta y_{C A}$ on the geometric error of the finished workpiece. 


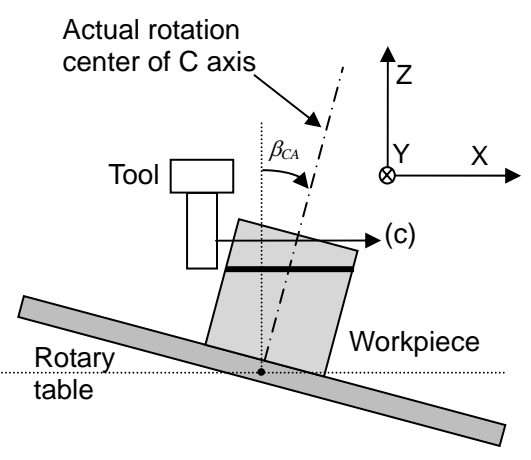

(a) At machining step (c). 


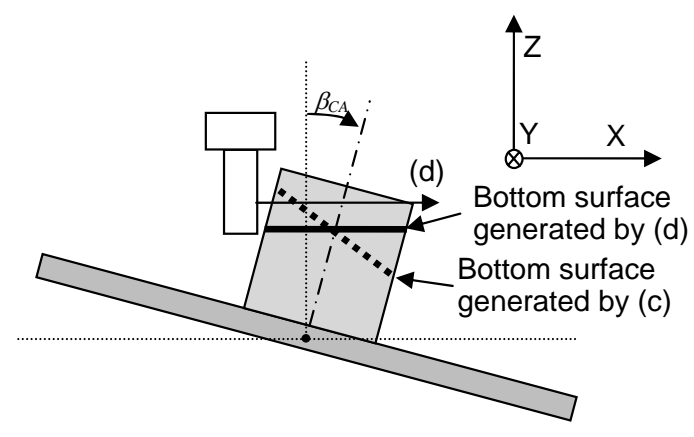

(b) At machining step (d).

Fig. 4. The influence of $\beta_{C A}$ on the geometric error of the finished workpiece. 


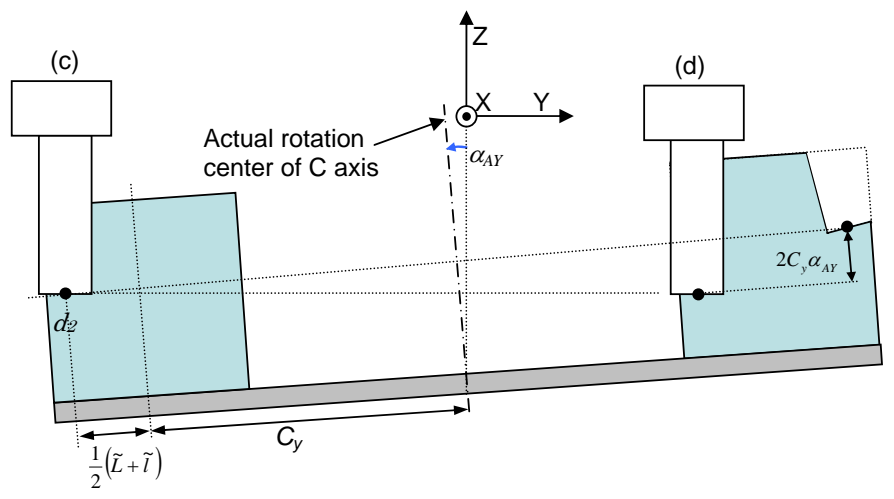

Fig. 5. The influence of $\alpha_{A Y}$ on the geometric error of the finished workpiece. 


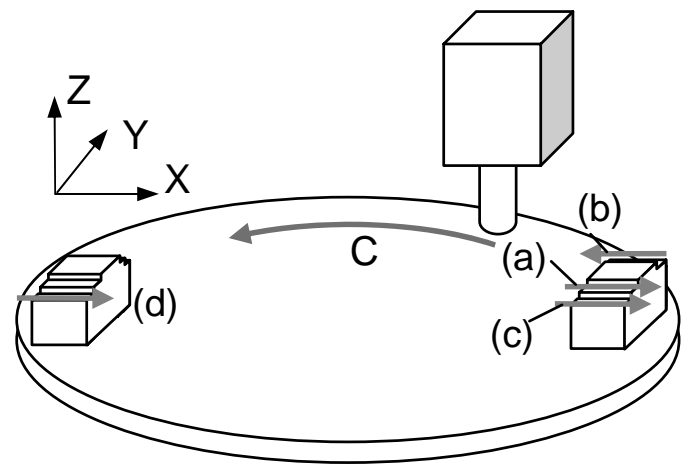

Fig. 6. Machining Pattern 1-b. 


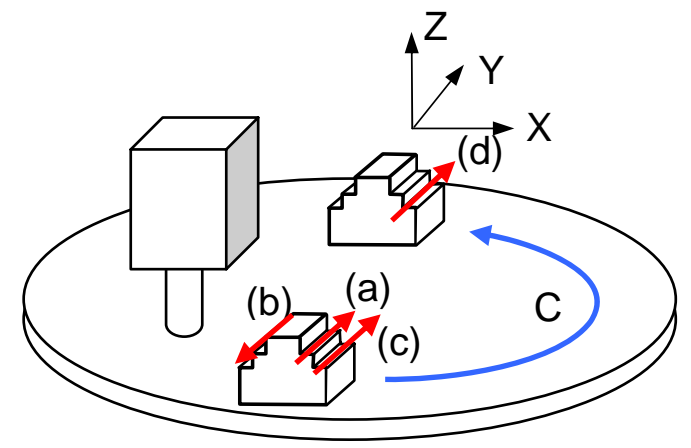

Fig. 7. Machining Pattern 2-a. 


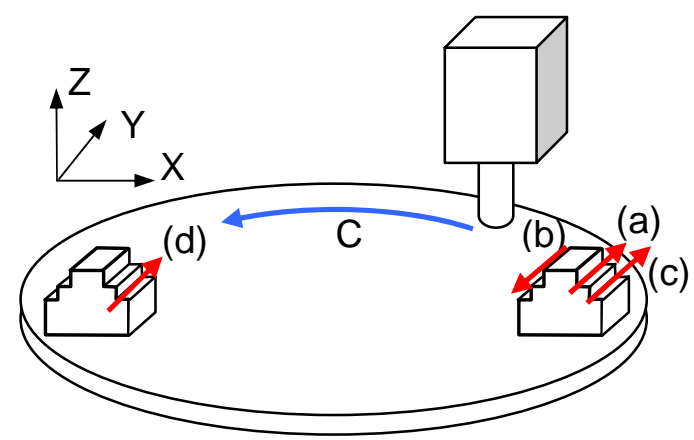

Fig. 8. Machining Pattern 2-b. 


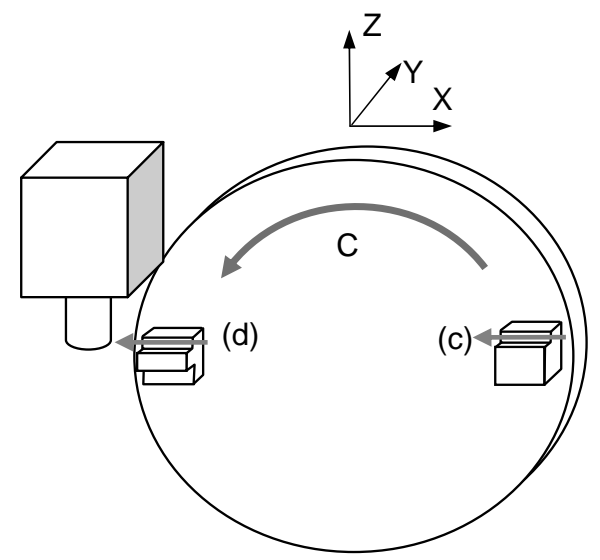

Fig. 9. Machining pattern 3. 


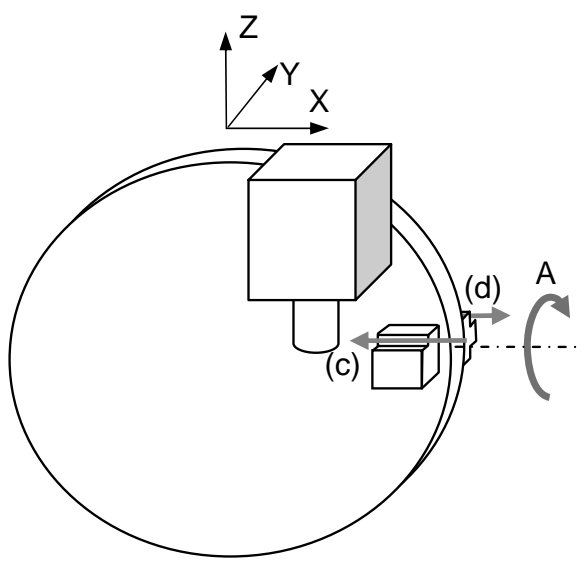

Fig. 10. Machining pattern 4. 


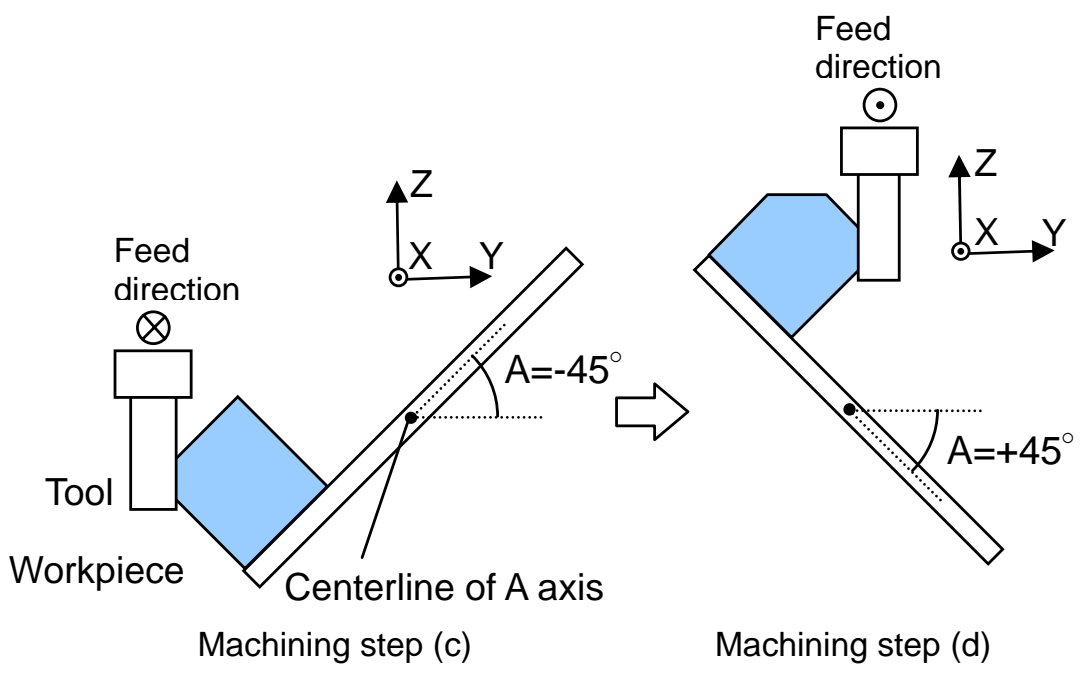

(a) Machining procedure. 


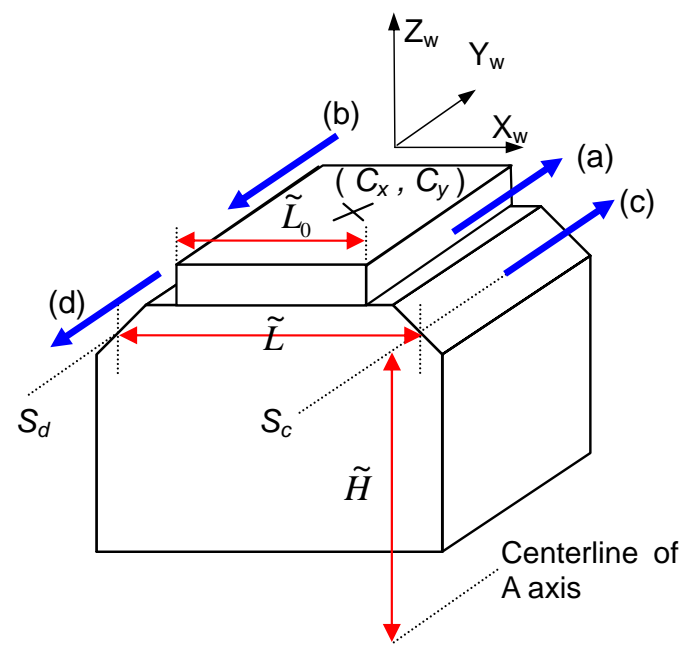

(b) Finished workpiece geometry.

Fig. 11. Machining pattern 5-a. 


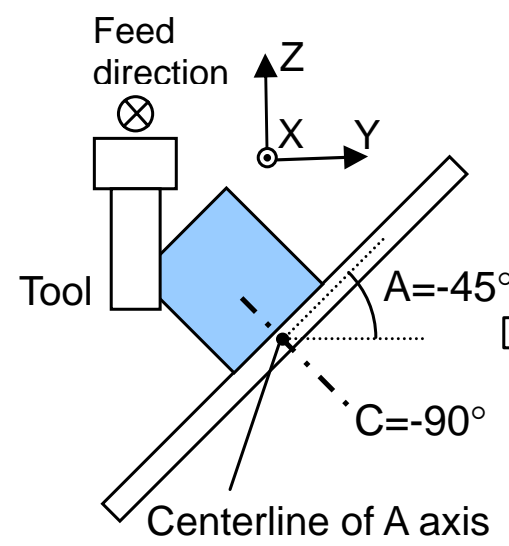

Machining step (c)

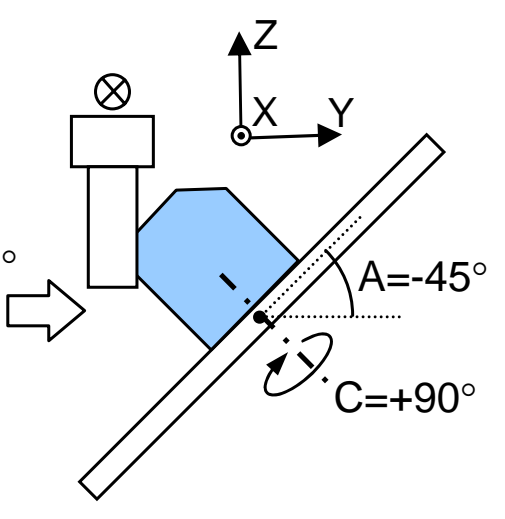

Machining step (d)

Fig. 12. Machining pattern 5-b. 


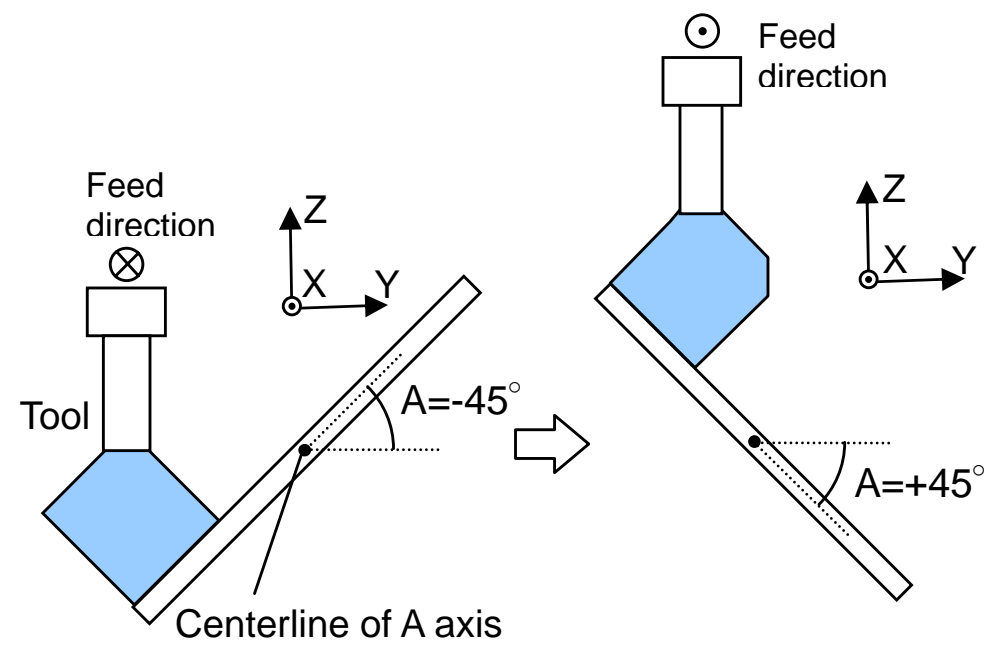

Machining step (c)

Machining step (d)

Fig. 13. Machining pattern 6-a. 

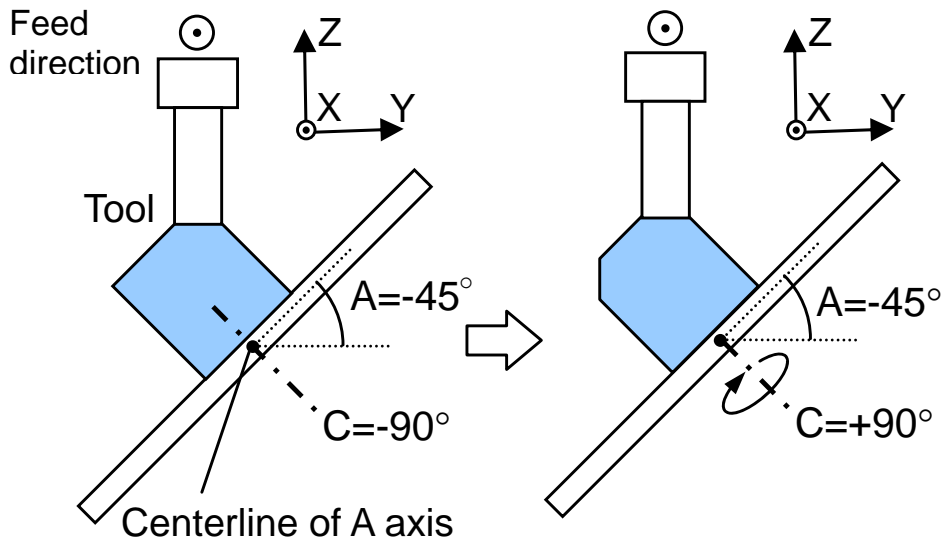

Machining step (c)

Machining step (d)

Fig. 14. Machining pattern 6-b. 


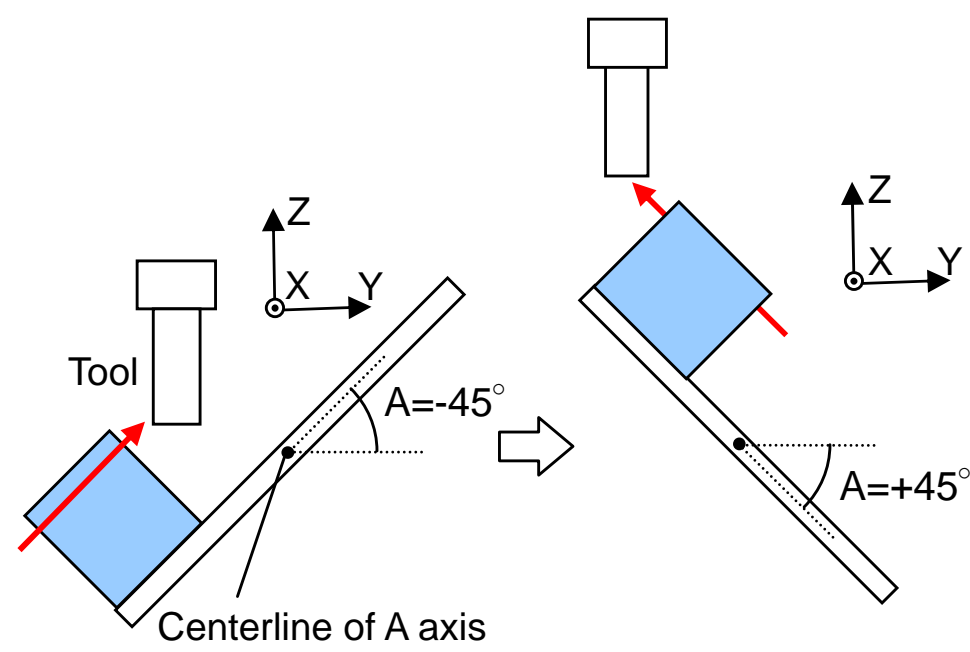

Machining step (c)

Machining step (d)

Fig. 15. Machining pattern 7. 

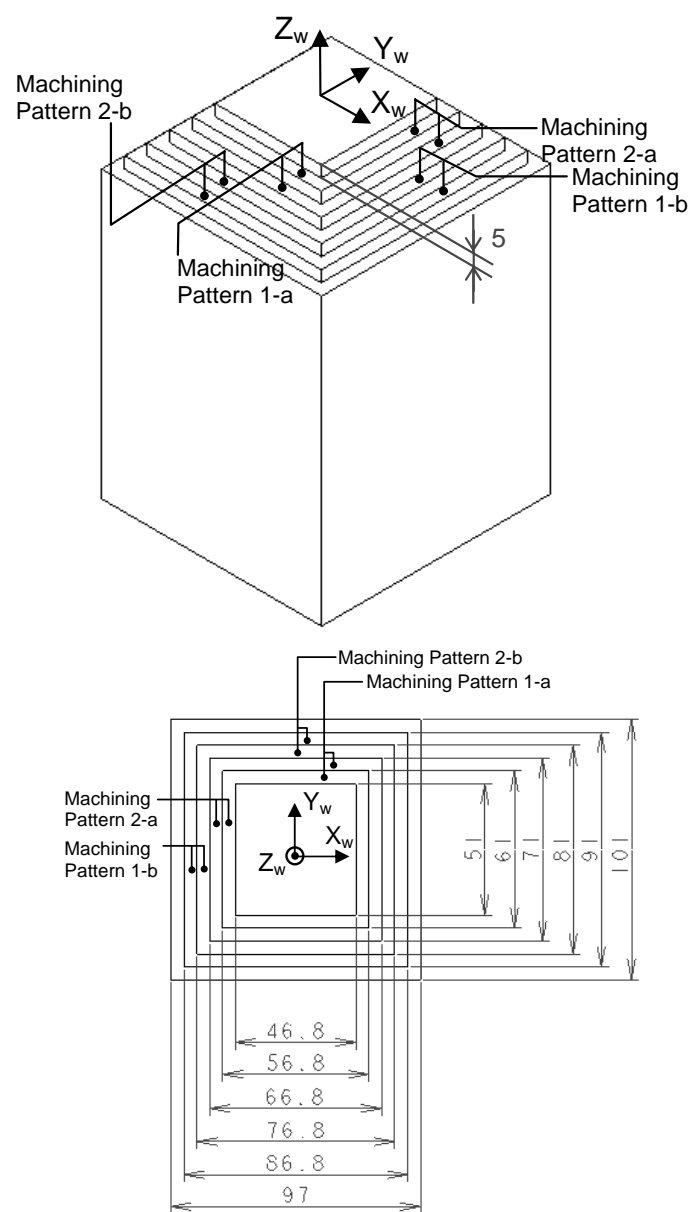

Fig. 16. The geometry of the finished Workpiece \#1. 

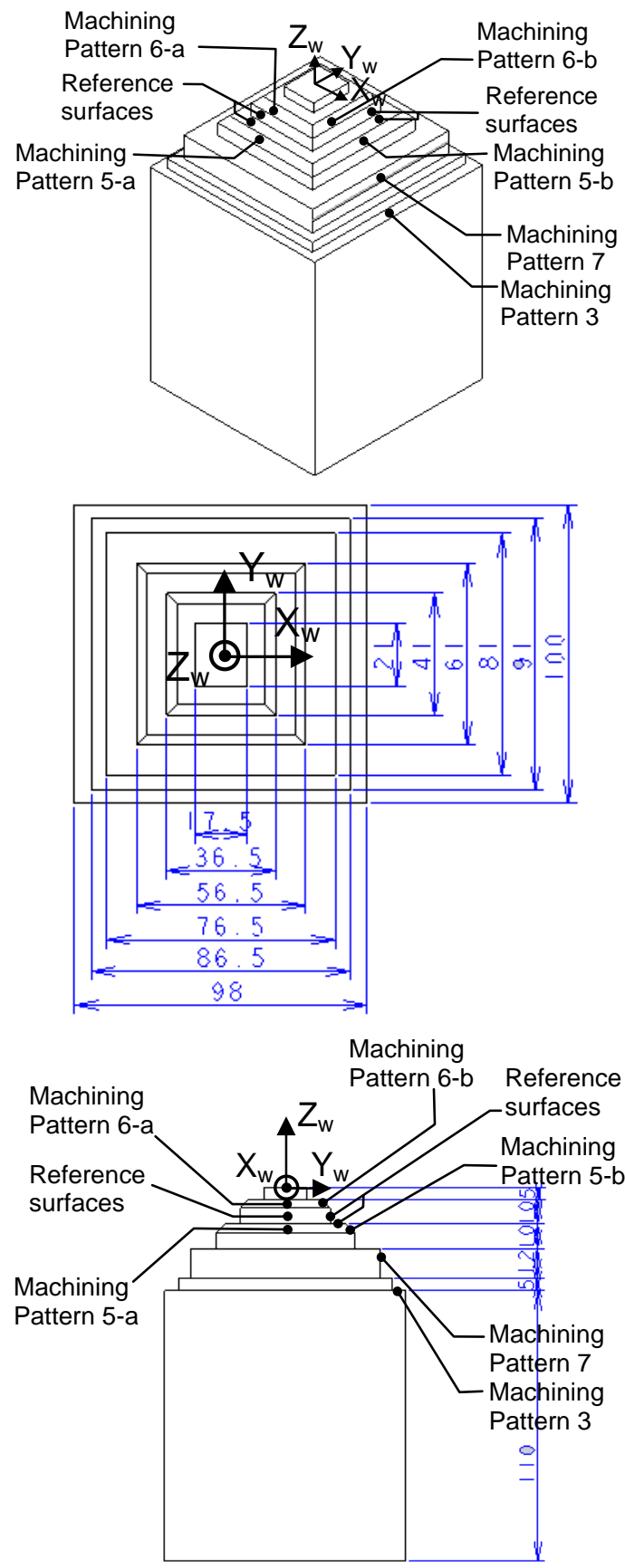

Fig. 17. The geometry of the finished Workpiece \#2. 

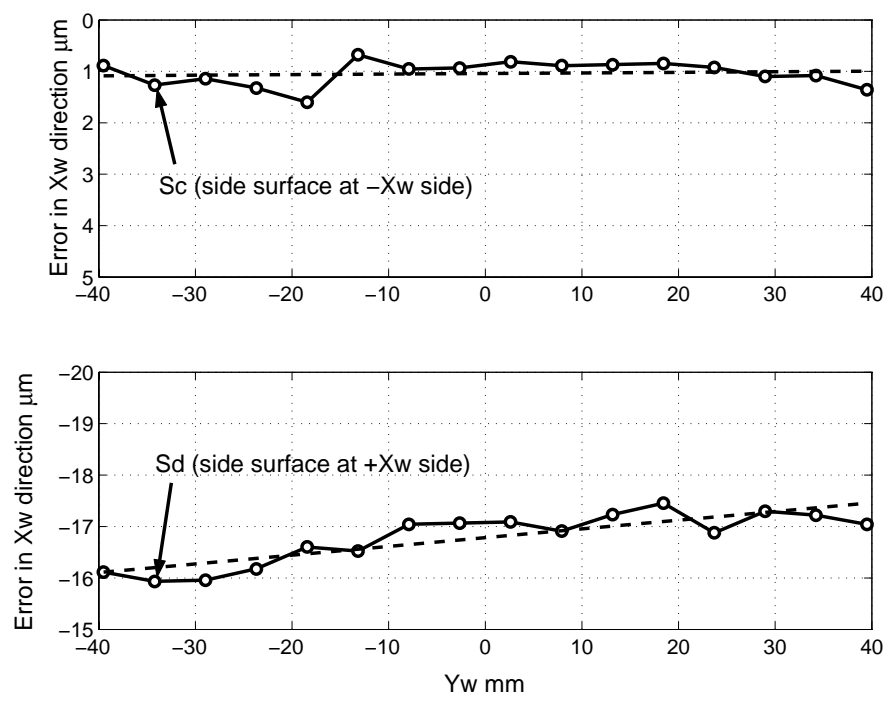

(a) Geometric error of side surfaces in the $X_{w}$ direction from their reference position. 


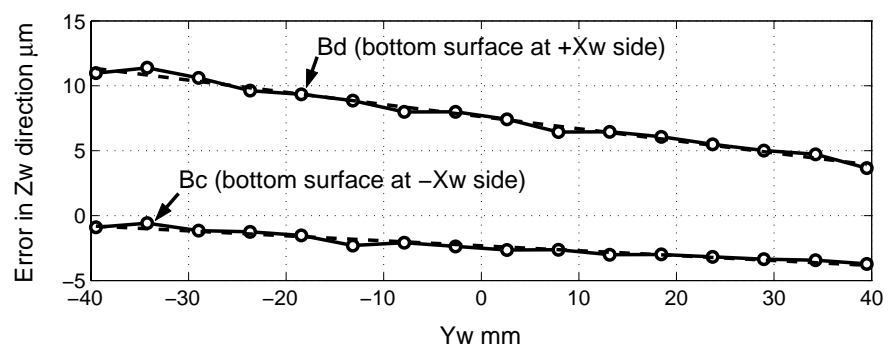

(b) Geometric error of bottom surfaces in the $Z_{w}$ direction from their reference position.

Fig. 18. Measured error profiles of workpiece surfaces machined by Machining Pattern 1-b.
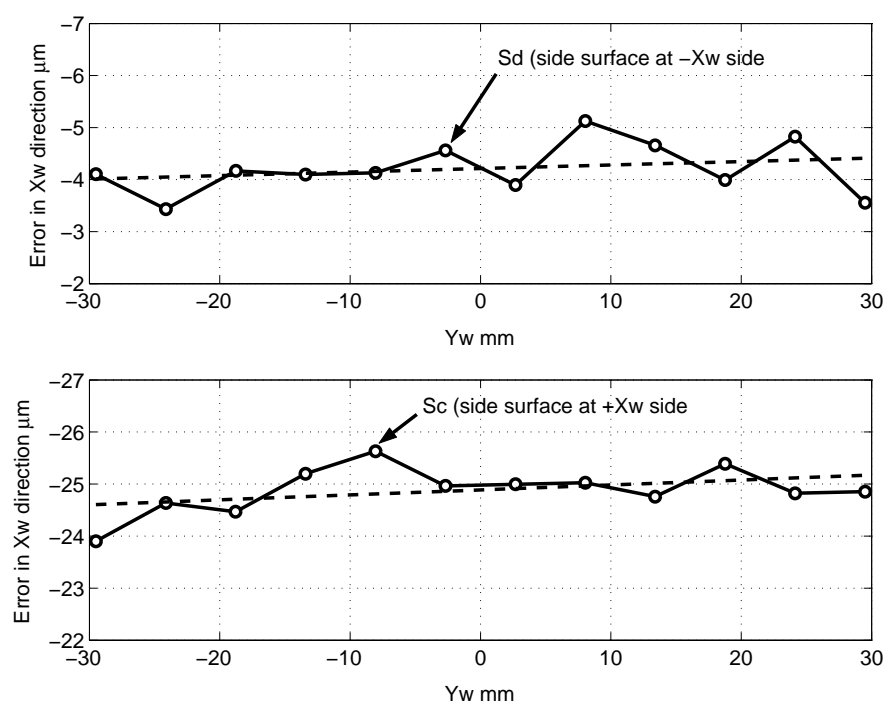

(a) Geometric error of side surfaces in the $X_{w}$ direction from their reference position. 


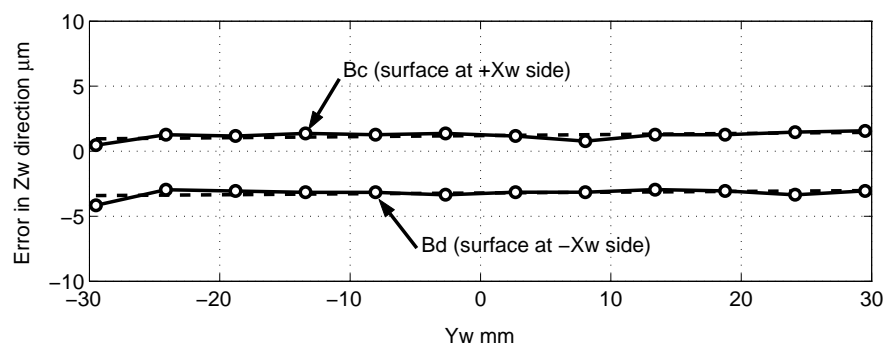

(b) Geometric error of bottom surfaces in the $Z_{w}$ direction from their reference position.

Fig. 19. Measured error profiles of workpiece surfaces machined by Machining Pattern 2-a.
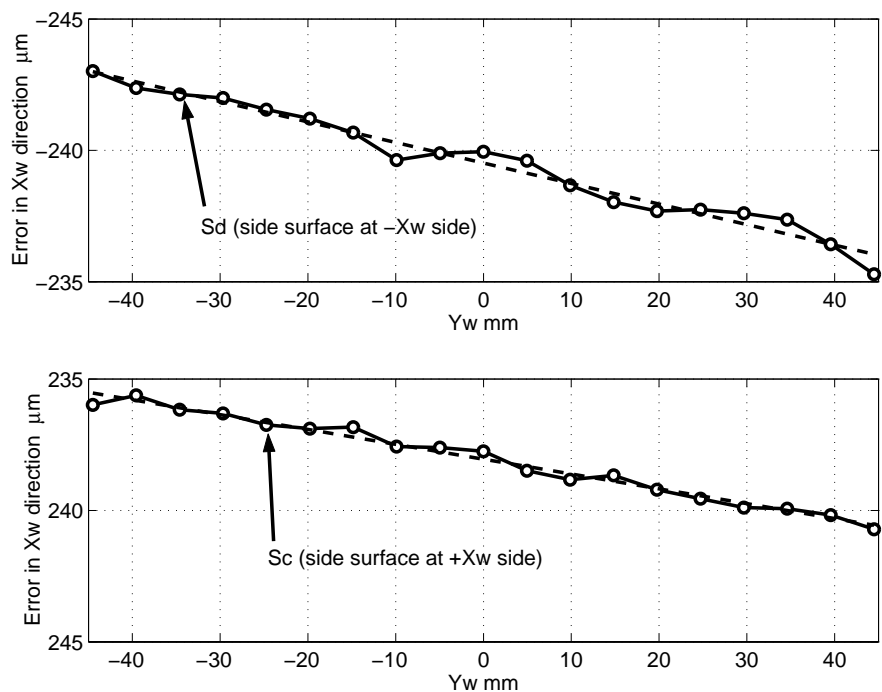

(a) Geometric error of side surfaces in the $X_{w}$ direction from their reference position. 


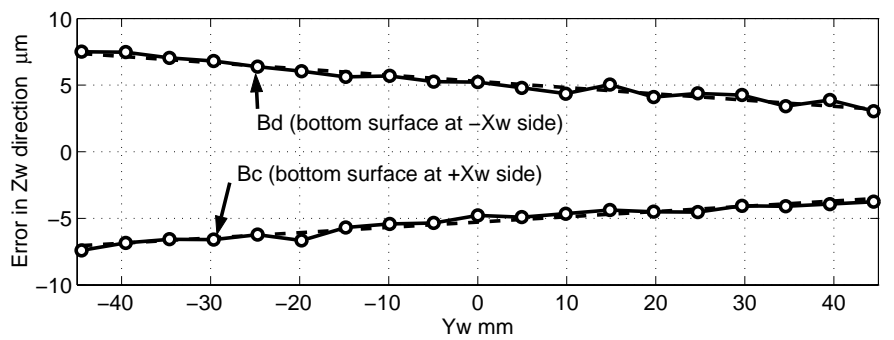

(b) Geometric error of bottom surfaces in the $Z_{w}$ direction from their reference position.

Fig. 20. Measured error profiles of workpiece surfaces machined by Machining Pattern 3. 